\title{
Reliability analysis of geosynthetic-reinforced steep slopes
}

\author{
F. B. Ferreira ${ }^{1}$, A. Topa Gomes², C. S. Vieira ${ }^{3}$ and M. L. Lopes ${ }^{4}$
}

${ }^{1}$ PhD candidate, CONSTRUCT-GEO, Faculty of Engineering, University of Porto, R. Dr. Roberto Frias, 4200-465 Porto, Portugal, Telephone: +351 225081286; Telefax: +351 225081446; E-mail: dec10027@fe.up.pt (Corresponding author)

${ }^{2}$ Assistant Professor, CONSTRUCT-GEO, Faculty of Engineering, University of Porto, R. Dr. Roberto Frias, 4200-465 Porto, Portugal, Telephone: +351 225081729; Telefax: +351 225081446; E-mail: atgomes@fe.up.pt

${ }^{3}$ Assistant Professor, CONSTRUCT-GEO, Faculty of Engineering, University of Porto, R. Dr. Roberto Frias, 4200-465 Porto, Portugal, Telephone: +351 225081586; Telefax: +351 225081446; E-mail: cvieira@fe.up.pt

${ }^{4}$ Professor, CONSTRUCT-GEO, Faculty of Engineering, University of Porto, R. Dr. Roberto Frias, 4200-465 Porto, Portugal, Telephone: +351 225081564; Telefax: +351 225081446; Email: Icosta@fe.up.pt

1 ABSTRACT: In slope stability analysis, the high degree of uncertainty associated with design parameters has led to increasing use of reliability-based approaches as a means of evaluating the combined effects of such uncertainties on the structure performance. In this study, the reliability level of geosynthetic-reinforced steep slopes designed according to Eurocode 7 (EC7), without any additional margin of safety, was assessed using the commercially-available Slide 6.0 software based on Monte Carlo simulation. To validate the EC7 partial factor design method regarding structural reliability, the estimated reliability indexes were compared with the minimum value recommended by Eurocode 0 (ECO). Additionally, through a probabilistic sensitivity analysis, the effect of variability in design parameters on slope reliability was evaluated and discussed. The results have shown that the geosynthetic-reinforced slopes designed to EC7 specifications exhibit generally an adequate reliability level according to ECO. 
The soil friction angle and the friction angle of the soil-geosynthetic interface and, secondly, the surcharge load, were found to be the most significant parameters for the reliability of the analysed slopes. For typical coefficients of variation of design parameters, the EC7 partial factor method tends to be conservative in terms of structural reliability. However, in situations of abnormal high variability, the partial factor methodology may lead to unsafe design, and thus reliability analyses should be implemented.

KEYWORDS: Geosynthetics, reliability analysis, geosynthetic-reinforced slope, Monte Carlo simulation method, probabilistic sensitivity analysis, Eurocodes, variability

\section{INTRODUCTION}

The absolute safety of a structure cannot be guaranteed. Uncertainty about loading and available resistance, limitations of design methods, use of simplifying assumptions and possible human errors during construction prevent accurate prediction of the structural behaviour and make it necessary to establish socially tolerable risk levels. The slope stability problem, in particular, is commonly associated with various sources of uncertainties, such as geological details missed in the site investigation phase, estimation of soil properties that are difficult to quantify (i.e. the spatial variability in the field cannot be accurately reproduced), variation in pore-water pressure, testing errors and many other important factors, which often cannot be eliminated by reasonable investigate effort or expenditure (Malkawi et al. 2000).

The conventional deterministic slope stability analyses consist of determining the global factor of safety for trial slip surfaces until the slip surface yielding the lowest factor of safety is located. These analyses are based on fixed representative values for design parameters, without explicit consideration of their inherent uncertainty and variability. The target factors of safety, empirically established (i.e. based on past experience), take into account all the uncertainties and risks involved in the design process. However, since it is common to use the same factor of safety value for a given type of application, such as long-term slope stability, without regard to the degree of uncertainty involved in its calculation, the same value of factor of safety is often applied to conditions that incorporate widely varying degrees of uncertainty 
(Duncan 2000). In fact, deterministic approaches suffer from several limitations such as the impossibility of establishing a direct relationship between the global factor of safety and the level of reliability of a structure and quantifying the impact of uncertainties in random input variables on the uncertainties of the model outputs.

Most current standards (including Structural Eurocodes) are based on semi-probabilistic safety concepts, using partial safety factors for actions and resistances. The principle behind semi-probabilistic safety analyses is that uncertainties are treated right at sources with the introduction of the "characteristic value" and the "design value" of the parameters, which have a statistical background. If the calculated design value for the effect of actions is lower than the calculated design value for the resistance, the design fulfils the ultimate limit state requirements. These analyses include the concepts of uncertainty and risk since there is a correspondence between the partial safety factors and the reliability index (or probability of failure). According to Eurocode 0 (ECO), a design using ECO with the partial factors given in Annex A1 and Eurocode 1 (EC1) to Eurocode 9 (EC9) is considered generally to lead to a structure with a reliability index value greater than 3.8 for a 50 -year reference period. Holicky and Vrouwenvelder (2005) stated that the most important advantage of the partial factor design method is the possibility of taking into account the uncertainty in individual variables by calibrating the relevant partial factors and other reliability elements. Cardoso and Fernandes (2001) highlighted the importance of a consistent and rational procedure for defining characteristic values for geotechnical parameters since the safety provided by the application of Eurocode 7 (EC7) depends not only on the partial safety factors specified by the code but also on the way the characteristic values are selected.

Probabilistic approaches and reliability analyses have been increasingly applied in slope stability assessment, as a powerful way of evaluating the combined effects of uncertainty and variability associated with soil and reinforcement strength parameters and loadings (e.g. Christian et al. 1994; Kitch 1994; Chowdhury and Xu 1995; Low and Tang 1997a; Griffiths et al. 2007, 2009, 2010; Cho 2010; Fenton and Griffiths 2010; Kitch et al. 2011, Javankhoshdel and Bathurst 2014). Within a probabilistic framework, the design parameters are treated as random variables and consequently, the calculated factor of safety is also regarded as a random 
variable with a probability distribution. The probability of failure and the reliability index may then be determined and used as performance indicators. Furthermore, probabilistic sensitivity analyses may help to evaluate the effect of variability in individual parameters and identify the most influential variables for the structure reliability. However, it is important to note that probabilistic modelling may be associated with difficulties due to the lack of available information, typical in geotechnical engineering (Beer et al. 2013). Thus, the simplest and most obvious advantage of a probabilistic approach or reliability analysis is to complement a conventional deterministic analysis by incorporating uncertainties associated with the performance of the geotechnical structure to be analysed, thereby allowing for an enhanced assessment of the structure reliability and providing an improved basis for interaction between engineers and decision-makers (Whitman 2000; Chowdhury et al. 2010).

Based on results of reliability analyses, risk assessment is often conducted to help geotechnical engineers in making informed decisions. From an engineering point of view, the risk is associated with the exposure of recipients to hazards and may be defined as the product of the probability of an adverse event and its consequences (Baecher and Christian 2003). In the context of risk analysis, consequence is the outcome or result of a hazard being realised and may include injury or loss of life, reconstruction costs, loss of economic activity, environmental losses, among others (Modarres 2006). The process of risk assessment consists of making a decision recommendation on whether existing risks are acceptable and present control risk measures are appropriate and, if not, whether alternative measures are justified or will be implemented. Therefore, risk assessment not only includes the risk analysis, which involves the definition of scope, danger identification, estimation of probability of occurrence, evaluation of the vulnerability of the elements at risk, consequence identification and risk estimation, but also incorporates the risk evaluation, the stage at which the values and judgement enter the decision process, by including consideration of the relevance of the estimated risks and the associated social, economic and environmental consequences (Fell et al. 2005).

This paper examines the structural reliability of nine geosynthetic-reinforced steep slopes designed according to EC7 (CEN 2004), without any additional margin of safety. The probability 
98

of failure and the reliability index are estimated using Slide 6.0 software (Rocscience Inc. 2010) based on Monte Carlo simulation. To validate the EC7 partial factor method regarding structural reliability, the obtained reliability levels are compared with the ECO (CEN 2002) recommended minimum value. Furthermore, through a probabilistic sensitivity analysis, the impact of variability in the input random variables on the slope reliability is investigated and the most significant design parameters are identified. This paper extends previous work on probabilistic slope stability analysis presented in Ferreira et al. (2013).

\section{RELIABILITY AND DESIGN UNDER UNCERTAINTY}

\subsection{The concept of structural reliability}

EC0 (CEN 2002) defines reliability as "the ability of a structure or a structural element to fulfil the specified requirements, including the design working life, for which it has been designed; reliability is usually expressed in probabilistic terms". Accordingly, reliability includes safety, serviceability and durability of a structure.

As a measure of reliability, ECO introduces the reliability index, which may be related to a probability of failure. In this context, "failure" includes not only catastrophic failure - as in the case of a landslide - but also any unacceptable difference between expected and observed performance (Leonards 1975; Baecher and Christian 2003). The relationship between the reliability index $(\beta)$ and the probability of failure (PF) can be expressed as (EC0):

$$
\mathrm{PF}=\Phi(-\beta)
$$

where $\Phi$ is the cumulative distribution function of the standardised normal distribution. Table 1 shows the relationship defined by Equation 1.

According to ECO, the probability of failure can be expressed through a performance function $g$ such that a structure is considered to survive if $g>0$ and fail if $g<0$. Consequently, if $g$ is normally distributed, the reliability index can be calculated as follows:

$$
\beta=\frac{\mu_{g}}{\sigma_{g}}
$$


where $\mu_{g}$ is the mean value of $g$ and $\sigma_{g}$ is the respective standard deviation. It is also noted that in this context, $\beta$ and PF are only notational values that do not necessarily represent the actual failure rates but are used as operational values for code calibration purposes and for comparison of reliability levels of structures.

The required level of reliability for a certain structure depends on the consequences that may arise from a hypothetic failure scenario. EC0 establishes three different Consequences Classes (CC) based on the potential damage in terms of loss of human life and social, economic or environmental impact (Table 2). For example, agricultural buildings where people do not normally enter are comprised in the $\mathrm{CC} 1$ class. Residential and office buildings are included in the CC2 class and grandstands or public buildings, where consequences of failure are high, integrate the CC3 class.

The Consequences Classes (CC1, CC2 and CC3) may be associated with the respective Reliability Classes (RC1, RC2 and RC3). For each Reliability Class, EC0 establishes recommended minimum values for the reliability index, as a function of the reference period (Table 3).

\subsection{Variability and uncertainty in geotechnical design}

Geotechnical variability is a complex attribute that results from many sources of uncertainties. There are three primary sources of geotechnical uncertainties: inherent variability, measurement errors and transformation uncertainties. Inherent variability arises mainly from the natural geologic processes that continually modify the in situ soil mass. Measurement errors are caused by equipment, procedure and/or operator and random testing effects. Equipment effects result from inaccuracies in the measuring devices and variations in equipment geometries and systems employed. Procedure and/or operator effects derive from the limitations in existing test standards and how they are followed. Random testing errors refer to the remaining scatter in the test results which is neither assignable to specific testing parameters nor caused by inherent soil variability. The third source of uncertainties (transformation uncertainties) is introduced 
when field or laboratory measurements are transformed into design properties using correlation models (Phoon and Kulhawy 1999; Phoon 2004).

In the context of reliability analysis, knowledge of distribution type and characterisation of variability in design parameters are important issues. Normal and lognormal distributions have been often used in geotechnical design to characterise variability in factor of safety (Duncan 2000; Koerner 2002; Sabatini et al. 2002), permeability, friction angle and unit weight of soil (Hoeg and Murarka 1974; Lacasse and Nadim 1996; Low and Tang 1997a, 1997b; Phoon and Kulhawy 1999; Chalermyanont and Benson 2004) and tensile strength of reinforcement (Low and Tang 1997a; Chalermyanont and Benson 2004). Table 4 indicates typical coefficients of variation (COV) for design parameters of particular interest for the current study, compiled on the basis of published data. Typical coefficients of variation for a broad variety of other soil properties may also be found in the literature (e.g. Lee et al. 1983; Phoon et al. 1995; Lacasse and Nadim 1996; Baecher and Christian 2003).

\subsection{Monte Carlo simulation method}

Several probabilistic methodologies are available for reliability-based design, namely the Monte Carlo simulation, First Order Second Moment method, Second Order Second Moment method, Point Estimate method, Hasofer-Lind approach (FORM), among others. Each method involves different computational effort, provides a different level of accuracy and yields a different insight into the effects of the individual parameters (Baecher and Christian 2003).

The Monte Carlo method provides approximate solutions to a variety of mathematical problems by performing statistical sampling experiments. The method uses randomly generated values for the component variables to determine the probability distribution of the design variable (e.g. factor of safety). Its application requires the knowledge of the statistical distribution of the input random variables. The steps for the implementation of the Monte Carlo method may be outlined as follows (Dai et al. 1993).

1. Generation of random numbers which are independent random variables uniformly distributed over the unit interval between zero and one. 
2. Transformation of the random numbers from a uniform distribution to the distribution applicable to the component variable.

3. Calculation of values of all component variables based on the appropriate random numbers.

4. Computation of the design variable (e.g. factor of safety) using the generated values of the component variables.

5. Repetition of steps 1. to 4. for a large number of times. The number of times these steps are repeated depends on the variability of the input and output parameters and the desired accuracy of the output.

6. Creation of a cumulative distribution of the design function using the data obtained from the above simulations.

The method is conceptually simple and has the capability of dealing with a wide range of functions, even those that cannot be expressed conveniently in explicit form. However, it has the disadvantage that it may converge slowly. Further details of this approach have been presented over recent decades by several authors, namely Hammersley and Handscomb (1964), Schreider (1966), Rubinstein (1981), Fishman (1996) and Baecher and Christian (2003).

\subsection{Probabilistic sensitivity analysis}

Sensitivity analyses have been widely applied in different areas of science and technology, such as engineering design, to investigate how a given model output depends upon the input parameters. This can be motivated simply by the wish of understanding the implications of a complex model but often arises due to the uncertainty about the true values that should be used for the input parameters (Oakley and O'Hagan 2004).

Among the different methods of sensitivity analysis, probabilistic sensitivity analysis is generally considered to be the most rigorous and is gaining widespread use. In design under uncertainty, probabilistic sensitivity analyses are typically performed to quantify the impact of uncertainties in random input variables (characterised by a probability distribution) on the 
204

uncertainty of the model output. Results from probabilistic sensitivity analyses have been used in engineering design for a range of purposes, including (Saltelli et al. 2000):

- reducing the dimension of a design problem by identifying the probabilistically insignificant factors;

- checking the validity of a model and the assumptions made on the probability distributions of the random inputs;

- obtaining insights into the design space and the probabilistic behaviour of a model response;

- investigating potential improvement on the probabilistic response by reducing the uncertainty in random inputs.

When applied to risk assessment, probabilistic sensitivity analyses can be very useful for understanding how risk estimates and, particularly, risk-based decisions are dependent on the variability and uncertainty in factors contributing to risk. In other words, sensitivity analyses can help to identify what is governing the risk estimates and, in these circumstances, contribute to risk mitigation by reducing the uncertainty related to the most relevant variables. This may be accomplished, for instance, by means of complementary geotechnical investigation (e.g. field investigation, laboratory testing, etc.).

\section{GEOSYNTHETIC-REINFORCED SLOPE MODELS}

In this study, nine geosynthetic-reinforced steep slopes designed according to EC7 (CEN 2004), without any additional margin of safety, were modelled and analysed using Slide 6.0 software (Rocscience Inc. 2010). The geometry of the reinforced slopes is shown in Figure 1. All nine slopes had height $H=8.4 \mathrm{~m}$ and were assumed to rest on competent foundations. The reinforcement layout consisted of fourteen horizontal geogrid layers with constant length $(L)$ and vertical spacing $s=0.6 \mathrm{~m}$ throughout the slope. For each slope, two geogrids with different tensile strengths were considered so that a stronger geogrid (GGR1) was used for the seven lower layers and a weaker geogrid (GGR2) was employed near the top of 
231

the structure. The backfill material was assumed to be a cohesionless granular soil with design unit weight $\gamma_{d}=23 \mathrm{kN} / \mathrm{m}^{3}$.

Three different slope angles were considered: $\alpha=60^{\circ}$ (Slopes 1 to 7 ), $\alpha=45^{\circ}$ (Slope 8 ) and $\alpha=75^{\circ}$ (Slope 9). For Slopes 1 to 4 , the design values of the soil internal friction angle $\left(\phi_{d}\right)$ were taken as $20^{\circ}, 25^{\circ}, 30^{\circ}$ and $35^{\circ}$, respectively, and no surcharge load was imposed. In the case of Slopes 5 to 7 , the design friction angles of the soil were respectively equal to $25^{\circ}, 30^{\circ}$ and $35^{\circ}$, but a uniform vertical surcharge $\left(S_{d}\right)$ of $13 \mathrm{kPa}$ (design value) was applied on the slope crest. Slopes 8 and 9 were also subjected to a surcharge load $S_{d}=13 \mathrm{kPa}$ and the design friction angle of the backfill material was set at $25^{\circ}$. The soil-geogrid interface friction angle $\left(\delta_{d}\right)$ was defined in terms of a $\delta_{d} / \phi_{d}$ ratio $\left(\delta_{d} / \phi_{d}=6 / 7\right)$ which was held constant for all slopes and both geogrid reinforcements (GGR1 and GGR2).

The design tensile strength ( $\left.T_{d}\right)$ of geogrids GGR1 and GGR2 and the reinforcement length provided were checked, following the design procedure proposed by Jewell $(1989,1996)$, so that the internal and overall equilibrium of the slopes was satisfied. It should be noted that Jewell's charts apply to reinforced slopes with a level crest and resting on a competent foundation, which is the case of the slopes herein investigated.

As previously mentioned, Structural Eurocodes adopt a semi-probabilistic approach for safety verification, using design values for actions and resistances. In a common design process, the design values of the variables would be determined from their characteristic values using partial safety factors. However, in the present study, the design values were defined first, to ensure that the design load was equal to the design strength. The characteristic values were then back-calculated, using partial safety factors in accordance with the Combination 2 of the Design Approach 1 of EC7 for verification of the ultimate limit state GEO (related to failure or excessive deformation of the ground) in persistent and transient situations. Since the code does not specify which partial safety factor should be used for the determination of the design tensile strength of geosynthetics, a partial safety factor meeting the requirements of the ISO/TR 20432:2007 (ISO 2007) was considered. 
The mean values of the design parameters to be used in the probabilistic stability analysis of the reinforced slopes were then determined, assigning a statistical distribution to the design parameters which were considered as random variables (soil unit weight, soil friction angle, soilgeogrid interface friction angle, tensile strength of geogrids and surcharge load). With the exception of the surcharge load, the variables were assumed to be normally distributed. Typical coefficients of variation were assigned to each of the distributions using data reported in the literature (see Table 4). For these variables, the characteristic values were assumed as quantiles of $5 \%$ or $95 \%$ of the statistical distributions depending on whether the parameters contribute to safety or not, respectively. The surcharge load was statistically characterised by an exponential distribution and its mean value was set equal to its characteristic value.

Table 5 presents the partial safety factors (PSF) and the coefficients of variation (COV) adopted in this study. Table 6 lists the design values (DV), the characteristic values (CHV) and the mean values (MV) of the design parameters for all the slopes analysed.

Using the simplified Bishop's method, which is one of the most commonly adopted limit equilibrium methods for slope stability analysis and is widely accepted as reasonably accurate, the deterministic Global Minimum circular slip surfaces and the ratio of the design strength to the design effect of actions (the so-called over-design factor) were obtained (Figures 2 to 10). Since the over-design factors are equal to unity, Slopes 1 to 9 fulfil the EC7 safety requirements, but no additional margin of safety is established.

\section{RELIABILITY ANALYSIS OF GEOSYNTHETIC-REINFORCED SLOPES}

There are two types of probabilistic stability analysis which may be carried out with Slide 6.0 software (Rocscience Inc. 2010): the Global Minimum method (fixed method) and the Overall Slope method (floating method). With the Global Minimum option, the probabilistic analysis is carried out only on the Global Minimum slip surface located by the deterministic slope stability analysis. The factor of safety of this single surface is recalculated $n$ times (where $n$ is the number of Monte Carlo simulations) using random values for the input parameters. The probability of failure is then computed as the number of analyses which result in a factor of safety less than unity, divided by the total number of samples. With this approach, the 
probability of failure (or the reliability index) of the deterministic Global Minimum slip surface is considered representative of the probability of failure for the slope.

With the Overall Slope analysis type, the entire search for a Global Minimum slip surface is repeated $n$ times. For each search iteration, a new set of random variables is first determined and the Global Minimum slip surface is then located. The Overall Slope reliability is based on the distribution of factors of safety obtained for all the Global Minimum slip surfaces located by the analysis. Since several Global Minimum slip surfaces are generally encountered, the probability of failure and the reliability index calculated for the overall slope are not associated with a specific slip surface. A potential advantage of the Overall Slope method, when compared with the Global Minimum method, is that it does not assume that the probability of failure of the slope is equal to the probability of failure of the deterministic Global Minimum slip surface. However, it involves a substantially greater computation time.

The application of the Monte Carlo simulation method requires that design parameters be characterised by their probability distributions, which describe the range of possible input values along with their probability of occurrence. As mentioned before, the unit weight $(\gamma)$ and friction angle $(\phi)$ of the soil, the soil-geogrid interface friction angle $(\delta)$, the tensile strength of the geogrids $(T)$ and the surcharge load $(S)$ were treated as random variables. The coefficients of variation for the input variables which were assumed to follow normal distributions $(\gamma, \phi, \delta$ and T) were previously indicated in Table 5. The mean values for all the design parameters were presented in Table 6. The surcharge load considered in the design of Slopes 5 to 9 was assigned an exponential distribution defined by a mean of $10 \mathrm{kPa}$ and minimum and maximum values respectively equal to $0 \mathrm{kPa}$ and $30 \mathrm{kPa}$, aiming to cover the high degree of uncertainty often associated with this variable.

Figure 11 illustrates the evolution of the reliability index of one example slope (Slope 5) as a function of the number of Monte Carlo simulations, obtained from the Global Minimum and Overall Slope methods. The number of random trials adopted $(n=1000000)$ was high enough to ensure the convergence of the simulations, and hence adequate accuracy in the results. This number of Monte Carlo simulations was maintained in all the analyses performed. 
Figures 12 and 13 compare additional data from the probabilistic stability analysis of Slope 5, carried out using the Global Minimum and Overall Slope options. The probability density functions and the cumulative probability distributions of the factor of safety determined from the former methods are presented in Figure 12. Figure 13 shows the values of the mean factor of safety, probability of failure and reliability index (assuming a normal distribution of the factor of safety results). The reliability indexes estimated from the Global Minimum and Overall Slope methods were respectively 4.141 (Figure 13a) and 4.130 (Figure 13b), which exceed the target value established by EC0 for structures of RC2 and a 50-year reference period ( $\beta=3.8)$. Also visible in Figure $13 \mathrm{~b}$ are the multiple Global Minimum slip surfaces which were located throughout the Overall Slope probabilistic analysis. Nevertheless, the difference between the results obtained from both methods is not significant (Figures 12 and 13), which may be attributed to the fact that the correlation between the factors of safety of different failure surfaces is very high. As pointed out by Cornell (1967), for the case of highly correlated failure modes, the contribution to the system probability of failure from failure surfaces other than that associated with the maximum probability of failure may be small, even though they are numerous. However, it has been mentioned in the literature that for cohesive soil slopes with spatial variability in the soil parameters, the overall probability of failure may be significantly higher than the probability of failure associated with a fixed critical slip surface (Cho 2010; Javankhoshdel and Bathurst 2014).

The results from the reliability analysis of the different slopes investigated in the current study are summarised in Table 7. Regardless of the reinforced slope considered, the different analysis types (Global Minimum and Overall Slope) provided quite similar results. It can be observed that the values of the factor of safety and the reliability index increased progressively with the slope angle (Slopes 8, 5 and 9), which is in agreement with the results reported by Kitch (1994) for two geogrid-reinforced slopes with slope angles of $45^{\circ}$ and $70^{\circ}$. The data presented in Table 7 also show that the reliability index decreased progressively as the friction angle of the soil was increased (Slopes 1 to 4 and Slopes 5 to 7 ). In other words, the reliability index was found to decrease as the relative contribution of the soil shear strength to the slope stability increased (i.e. when the soil friction angle increased, and hence the required 
344

reinforcement contribution to strength decreased) and, on the other hand, it was found to increase when the relative contribution of the reinforcement tensile strength to the slope stability increased (i.e. when the slopes became steeper and the tensile strength of the geogrids was increased so as to ensure the slope stability). This may be justified by the fact that the coefficient of variation of the soil friction angle $(\mathrm{COV}=7 \%)$ was higher than that of the geogrid tensile strength $(\mathrm{COV}=5 \%)$, and thus decreasing the uncertainty associated with the strength properties increases the reliability index and vice-versa.

For the number of simulations performed $(n=1000000)$, all the factors of safety obtained corresponded to safe situations ( $F S \geq 1$ ), and hence the computed probabilities of failure for Slopes 1 to 9 were equal to zero (Table 7). In any case, even considering the normal distribution fit for this zone, the number of points in the vicinity of FS = 1 was limited. To more accurately characterise the probability of failure using the Monte Carlo method, the use of a technique able to generate a relevant number of sets of values for design parameters resulting in a factor of safety close to unity would be required.

As shown in Table 7, with the exception of Slopes 4 and 7, whose soil friction angle was the highest considered in this study $\left(\phi_{d}=35^{\circ}\right)$, the reliability indexes for the different geogridreinforced slopes were greater than the ECO recommended minimum value $(\beta=3.8)$. This finding supports the idea that, for common structures, the EC7 partial factor design method tends to be conservative from the point of view of structural reliability.

\section{PROBABILISTIC SENSITIVITY ANALYSIS}

\subsection{General}

In design under uncertainty, probabilistic sensitivity analyses are commonly performed to evaluate the effect of variability in random input parameters on the probabilistic characteristics of a design performance. Results from probabilistic sensitivity analyses may be particularly useful when used as a design aid in decision making for selecting the most suitable design based on specific project constraints (e.g. target cost or schedule). 
In the present study, Slide 6.0 software was used to perform a probabilistic sensitivity analysis of the variability associated with the design parameters of Slopes $5,6,8$ and 9 . The primary objectives of this analysis were the following: to ascertain how the variability in design parameters influences the reliability level of geosynthetic-reinforced steep slopes with different slope angles and soil friction angles; to identify the most relevant parameters regarding the reliability of these structures; and to assess the level of safety margin of the EC7 partial factor method with respect to structural reliability, which may be of particular importance in the absence of clear information concerning the variability associated with design parameters.

To perform the sensitivity analysis, different COVs around the most likely value (the value adopted in the reliability analysis presented in the previous section) were assigned to soil and reinforcement parameters $(\gamma, \phi, \delta$ and $T)$ on the basis of published data (see Table 4). With respect to the surcharge load $(S)$, the analysis was carried out by varying the upper bound value. Table 8 indicates the COVs and surcharge limits considered. For each soil or reinforcement parameter, its COV was varied within the considered range, while the COVs corresponding to the remaining parameters and the surcharge limits were held constant at their most likely values. Similarly, for the probabilistic sensitivity analysis of the variability associated with the surcharge load, the COVs of the soil and reinforcement parameters were kept constant and equal to their most likely values. For each combination of COVs and surcharge limits, a probabilistic stability analysis (using the Global Minimum option) with 1000000 Monte Carlo simulations was performed and the model response was evaluated. Given the similarity between the results obtained from the Global Minimum and Overall Slope methods in the previous probabilistic analyses (see section 4), the added computation time required to carry out the sensitivity analyses using the Overall Slope option seemed unwarranted.

\subsection{COV of soil unit weight}

Table 9 presents the results of the probabilistic sensitivity analysis carried out to investigate how the uncertainty in the soil unit weight may affect the reliability of Slopes 5, 6, 8 and 9, in terms of the mean factor of safety, probability of failure and reliability index. 
From Table 9 it can be concluded that the variation of the COV of the soil unit weight from $1 \%$ to $10 \%$ did not significantly affect the reliability level of the reinforced slopes, which could be expected since the soil weight influences both the normal and shear forces acting on each slice. In fact, although a slight reduction in the reliability index may be identified, the values of the mean factor of safety obtained for each slope remained nearly constant as the COV of the soil unit weight was increased. Furthermore, it is possible to observe that all the calculated reliability indexes were above the EC0 reference value for a structure of RC2 and a 50-year reference period $(\beta=3.8)$. These results suggest that, for conditions similar to those adopted in this study, a reinforced slope designed according to the partial factor method proposed by EC7 maintains an adequate level of reliability even if the real COV of the soil unit weight reaches $10 \%$, provided that the variability in the remaining design parameters corresponds to the expected value (the value considered in the slope design).

\subsection{COV of soil friction angle and soil-geogrid interface friction angle}

The influence of the simultaneous variation of the COV of the soil friction angle and soilgeogrid interface friction angle was evaluated by using different COVs ranging from $2 \%$ to $15 \%$. The results from these simulations are shown in Table 10. The probability of failure and the reliability index for all four slopes were significantly affected by the increase in the variability associated with the shear strength of the soil and soil-geogrid interface. When the COV of the friction angles was increased up to $10 \%$ or $15 \%$, the values of the reliability index fell below the ECO reference value and the probability of failure reached maximum values of about $1.2 \%$, $1.6 \%, 2.1 \%$ and $0.4 \%$ for Slopes $5,6,8$ and 9 , respectively. These results suggest that the friction angles of soil and soil-geogrid interface play a decisive role on the slope reliability, regardless of the slope angle. Kitch (1994) and Kitch et al. (2011) obtained a similar conclusion regarding the effect of the variability in the soil shear strength on the reliability of geogridreinforced slopes, using the first-order reliability method (FORM). Thus, in the design and stability analysis of geosynthetic-reinforced steep slopes, efforts should be made in order to properly characterise the uncertainty associated with the soil and soil-geosynthetic interface 
shear strength, which may be accomplished by means of direct shear tests on soil and soilgeosynthetic pullout and direct shear tests (e.g. Sukmak et al. 2015; Hatami and Esmaili, 2015; Ferreira et al. 2015a, 2015b), using the specific materials to be used on the project. The obtained results also suggest that a reinforced slope designed according to EC7, without any additional margin of safety, will probably not be a reliable structure (according to ECO) if the real COVs of the soil and interface friction angles reach values higher than those adopted in the slope design.

\subsection{COV of geogrid tensile strength}

In order to understand how the variability in the geogrid tensile strength may affect the reliability of geogrid-reinforced steep slopes designed according to EC7, different COVs in the range of $1 \%$ to $10 \%$ were assigned to this variable (Table 11 ). The results presented in Table 11 demonstrate that the variation of the COV of the geogrid tensile strength over the considered range did not have a relevant influence on the mean factor of safety, probability of failure and reliability index of these particular slopes. Despite being of little importance, the influence of the variability in the geogrid tensile strength on the obtained reliability indexes increased with the slope angle (Slopes 8, 5 and 9), which is consistent with the results presented by Kitch (1994) and Kitch et al. (2011). Regardless of the variability in the geogrid tensile strength, the values of the reliability index were greater than the ECO recommended value for structures of RC2 and a reference period of 50 years $(\beta=3.8)$. Therefore, the geogrid tensile strength is not considered to be a significant design parameter with respect to the structural reliability of the analysed slopes. However, this is probably related to the fact that the mobilised tensile strength of the geogrids is well below their design strength. In cases where the previous values are closer, the variability in the geogrid tensile strength may have much more impact on slope reliability. As shown by Kitch (1994) and Kitch et al. (2011), for internal failure modes (critical slip surfaces passing predominantly through the reinforced portion of the slope), the variability in the geogrid tensile strength may have a marked influence on the reliability level of geogrid-reinforced slopes. 


\subsection{Upper limit of the surcharge load}

The effect of the variability in a surcharge load (with a mean value of $10 \mathrm{kN} / \mathrm{m}^{2}$ ) applied on the top of the slopes was studied by defining different upper bound values for the corresponding exponential probability distribution (from $15 \mathrm{kPa}$ to $50 \mathrm{kPa}$ ). The results from this sensitivity analysis are presented in Table 12. As can be noted from the table, the increase in the variability of the surcharge load induced a small reduction in the reliability index of the slopes. Moreover, it is important to highlight that for Slopes 6 and 8 , the reliability index obtained when the upper limit of the surcharge load was set at $50 \mathrm{kPa}$ was slightly lower than the EC0 recommended minimum value $(\beta=3.8)$.

\subsection{Limit combinations}

In order to better understand to what extent the combined variability in the design parameters may affect the reliability of geosynthetic-reinforced slopes, two additional combinations were analysed in which the variability in all the input parameters was set very low or abnormally high (Table 13).

From Table 13 it can be concluded that if the variability associated with all the design parameters is very low, the reliability index of each slope more than triplicates the value obtained from the probabilistic analysis in which the most likely COVs and surcharge limits were considered. In contrast, as would be expected, if the variability is abnormally high, the probability of failure substantially increases and the reliability index undergoes a sharp reduction. As shown in Table 13, the minimum reliability index obtained for the studied slopes was about 1.8, which is less than half the value recommended by EC0 for structures of RC2 and a reference period of 50 years, corresponding to totally unacceptable probabilities of failure.

\section{CONCLUSIONS}

This paper investigates the structural reliability of geosynthetic-reinforced steep slopes designed according to EC7 (without any additional margin of safety), using the Monte Carlo method, and compares the estimated levels of reliability with the ECO recommended minimum 
value. A probabilistic sensitivity analysis is then performed, enabling the evaluation of the effect of the variability associated with input random variables (i.e. soil and reinforcement parameters and loadings) on slope reliability. Based on the obtained results, the following conclusions can be drawn.

Among the nine geosynthetic-reinforced steep slopes analysed in this study, seven exhibited a reliability index greater than the ECO recommended minimum value for structures of Reliability Class 2 and a reference period of 50 years $(\beta=3.8)$. Only those whose soil friction angle was the highest herein considered (design value of $35^{\circ}$ ) presented a reliability index slightly lower than the ECO target value. Therefore, for usual values of design parameters, the EC7 partial factor method leads generally to a structure meeting the EC0 requirements in terms of structural reliability.

Since the variability and uncertainty associated with the reinforcement strength is typically lower that that related to the ground strength properties, the reliability index of the geosyntheticreinforced slopes decreased as the relative contribution of the soil shear strength to the slope stability increased (i.e. when the soil friction angle increased, and consequently the required reinforcement contribution to strength decreased) and, on the other hand, it increased when the relative contribution of the reinforcement strength to the slope stability increased (i.e. when the slopes became steeper and the tensile strength of the geogrids was increased so as to ensure the slope stability).

No relevant differences between the results of the reliability analyses carried out using fixed or floating probabilistic methods (i.e. the Global Minimum and Overall Slope methods available in Slide 6.0 software) were observed.

The probabilistic sensitivity analysis of the variability associated with the input random variables revealed that the soil friction angle and that of the soil-geosynthetic interface and, secondly, the surcharge load, were the design parameters that had the most influence on the reliability of the investigated slopes. Therefore, in design and stability analysis of geosyntheticreinforced slopes, efforts should be directed at reducing the uncertainty associated with such parameters. 
511

For common variability in design parameters, the EC7 partial factor method tends to be conservative from the point of view of reliability. In any case, for situations where the variability in the input parameters reaches abnormal high values, the partial factor methodology may lead to unsafe design, and hence reliability analyses should be implemented.

\section{ACKNOWLEDGMENTS}

The authors would like to acknowledge the financial support from the Portuguese Foundation for Science and Technology (FCT) under Grant SFRH/BD/72886/2010 and Research Projects FCOMP-01-0124-FEDER-009750-PTDC/ECM/100975/2008 and FCOMP-01-0124-FEDER028842-PTDC/ECM-GEO/0622/2012.

\section{NOTATION}

Basic SI units are given in parentheses.

$$
H \text { - slope height }(\mathrm{m})
$$

$L-$ reinforcement length $(\mathrm{m})$

$n$ - number of Monte Carlo simulations (dimensionless)

$s-$ vertical spacing of reinforcement layers $(\mathrm{m})$

$S$ - surcharge load $\left(\mathrm{N} / \mathrm{m}^{2}\right)$

$S_{d}$ - design value of surcharge load $\left(\mathrm{N} / \mathrm{m}^{2}\right)$

$T$ - geogrid tensile strength $(\mathrm{N} / \mathrm{m})$

$T_{d}-$ design value of geogrid tensile strength $(\mathrm{N} / \mathrm{m})$

$\alpha$-slope angle (degrees)

$\beta$ - reliability index (dimensionless)

$\gamma$ - soil unit weight $\left(\mathrm{N} / \mathrm{m}^{3}\right)$

$\gamma_{d}-$ design value of soil unit weight $\left(\mathrm{N} / \mathrm{m}^{3}\right)$

$\delta$ - soil-geosynthetic interface friction angle (degrees)

$\delta_{d}-$ design value of soil-geosynthetic interface friction angle (degrees)

$\phi$ - soil friction angle (degrees) 


\section{ABBREVIATIONS}

542

$\mathrm{CC}-$ Consequences Class

$543 \mathrm{CHV}-$ characteristic value

544 COV - coefficient of variation

545 DV - design value

546 ECO - Eurocode 0 (CEN 2002)

547 EC7 - Eurocode 7 (CEN 2004)

548 FS - factor of safety

549 GEO - ultimate limit state related to failure or excessive deformation of the ground (EC7)

550 GGR - geogrid

$551 \quad$ MV - mean value

$552 \quad$ PF - probability of failure

553 PSF - partial safety factor

554 RC - Reliability Class

555

556

\section{REFERENCES}

557 Baecher, G.B. \& Christian, J.T. (2003). Reliability and Statistics in Geotechnical Engineering. John Wiley \& Sons, New York, $605 \mathrm{p}$.

Beer, M., Zhang, Y., Quek, S.T. \& Phoon, K-K. (2013). Reliability analysis with scarce information: comparing alternative approaches in a geotechnical engineering context. Structural Safety, 41: 1-10.

Cardoso, A.S. \& Fernandes, M.M. (2001). Characteristic values of ground parameters and probability of failure in design according to Eurocode 7. Géotechnique, 51(6): 519-531.

564 Chalermyanont, T. \& Benson, C.H. (2004). Reliability-based design for internal stability of 565 mechanically stabilized earth walls. Journal of Geotechnical and Geoenvironmental Engineering, 130(2): 163-173. 
567

Cho, S.E. (2010). Probabilistic assessment of slope stability that considers the spatial variability of soil properties. Journal of Geotechnical and Geoenvironmental Engineering, 136(7): 975984.

Chowdhury, R.N., Flentje, P. \& Bhattacharya, G. (2010). Geotechnical Slope Analysis. CRC Press/ Balkema, Taylor \& Francis Group, The Netherlands, 772 p.

Chowdhury, R.N. \& Xu, D.W. (1995). Geotechnical system reliability of slopes. Reliability Engineering and System Safety, 47: 141-151.

Christian, J.T., Ladd, C.C. \& Baecher, G.B. (1994). Reliability applied to slope stability analysis. Journal of Geotechnical Engineering, 120(12): 2180-2207.

Cornell, C.A. (1967). Bounds on the reliability of structural systems. Journal of the Structural Division, ASCE, 93(1): 171-200.

Dai, Y., Fredlund, D.G. \& Stolte, W.J. (1993). A probabilistic slope stability analysis using deterministic computer software. Proceedings of Conference on Probabilistic Methods in Geotechnical Engineering, Canberra, Australia, pp. 267-274.

Duncan, J.M. (2000). Factors of safety and reliability in geotechnical engineering. Journal of Geotechnical and Geoenvironmental Engineering, 126(4): 307-316.

CEN (2002). EN 1990:2002. Eurocode - Basis of structural design. European Committee for Standardization, Brussels, Belgium.

CEN (2004). EN 1997-1:2004. Eurocode 7 - Geotechnical design. European Committee for Standardization, Brussels, Belgium.

Fell, R., Ho, K.K., Lacasse, S. \& Leroi, E. (2005). A framework for landslide risk assessment and management. Landslide Risk Management, Cruden, D.M. \& Fell, R., Editors, Balkema, Rotterdam, pp. 3-25.

Fenton, G.A. \& Griffiths, D.V. (2010). Reliability-based geotechnical engineering. Proceedings of GeoFlorida 2010: Advances in Analysis, Modelling \& Design, Orlando, Florida, USA, February 2010, pp. 14-52.

Ferreira, F.B., Topa Gomes, A., Vieira, C.S. \& Lopes, M.L. (2013). Probabilistic stability analysis of a geogrid reinforced steep slope. Proceedings of Geosintec Iberia 1, Seville, Spain, November 2013, pp. 73-80. 
596

597

598

599

600

601

602

603

604

605

606

607

608

609

610

611

612

613

614

615

616

617

618

619

620

621

622

623

624

Ferreira, F.B., Vieira, C.S. \& Lopes, M.L. (2015a). Direct shear behaviour of residual soilgeosynthetic interfaces - influence of soil moisture content, soil density and geosynthetic type. Geosynthetics International, 22(3): 257-272.

Ferreira, F.B., Vieira, C.S., Lopes, M.L. \& Carlos, D.M. (2015b). Experimental investigation on the pullout behaviour of geosynthetics embedded in a granite residual soil. European Journal of Environmental and Civil Engineering (DOI: 10.1080/19648189.2015.1090927).

Fishman, G.S. (1996). Monte Carlo: Concepts, Algorithms, and Applications. Springer-Verlag, New York, USA, 698 p.

Griffiths, D.V., Fenton, G.A. \& Denavit, M.D. (2007). Traditional and advanced probabilistic slope stability analysis. Proceedings of Geo-Denver 2007, Probabilistic Applications in Geotechnical Engineering, Denver, Colorado, USA, February 2007, pp. 1-10.

Griffiths, D.V., Huang, J. \& Fenton, G.A. (2009). Influence of spatial variability on slope reliability using 2-D random fields. Journal of Geotechnical and Geoenvironmental Engineering, 135: 1367-1378.

Griffiths, D.V., Huang, J. \& Fenton, G.A. (2010). Comparison of slope reliability methods of analysis. Proceedings of GeoFlorida 2010: Advances in Analysis, Modelling \& Design, Orlando, Florida, USA, February 2010, pp. 1952-1961.

Griffiths, D.V., Huang, J. \& Wolfe, G. (2011). Numerical and analytical observations on long and infinite slopes. International Journal for Numerical and Analytical Methods in Geomechanics, 35: 569-585.

Hammersley, J.M. \& Handscomb, D.C. (1964). Monte Carlo Methods. Chapman and Hall, London, England, $178 \mathrm{p}$.

Harr, M.E. (1984). Reliability-based design in civil engineering. $20^{\text {th }}$ Annual Henry M. Shaw Lecture Series in Civil Engineering, North Carolina State University, School of Engineering, Raleigh, N.C., USA.

Hatami, K. \& Esmaili, D. (2015). Unsaturated soil-woven geotextile interface strength properties from small scale pullout and interface tests. Geosynthetics International, 22(2): 161-172.

Hoeg, K. \& Murarka, R. P. (1974). Probabilistic analysis and design of a retaining wall. Journal of the Geotechnical Engineering Division, ASCE, 100(3): 349-366. 
625

Holicky, M. \& Vrouwenvelder, T. (2005). Basic Concepts of Structural Reliability. Chapter I of the Handbook 2 - Reliability Backgrounds. Leonardo Da Vinci Pilot Project CZ/02/B/F/PP 134007.

ISO (2007). ISO/TR 20432:2007. Guidelines for the determination of the long-term strength of geosynthetics for soil reinforcement. International Organization for Standardization, Geneva, Switzerland.

Javankhoshdel, S. \& Bathurst, R.J. (2014). Simplified probabilistic slope stability design charts for cohesive and cohesive-frictional (c- $\phi)$ soils. Canadian Geotechnical Journal, 51: 10331045.

Jewell, R.A. (1989). Revised design charts for steep reinforced slopes. Proceedings of Reinforced Embankments: Theory and Practice, Cambridge, England, September 1989, pp. $1-30$.

Jewell, R.A. (1996). Soil reinforcement with geotextiles. Special Publication 123, CIRIA and Thomas Telford, $332 \mathrm{p}$.

Kitch, W.A. (1994). Deterministic and probabilistic based analyses of reinforced soil slopes. PhD Thesis, The University of Texas at Austin, $383 \mathrm{p}$.

Kitch, W.A., Gilbert, R.B. \& Wright, S.G. (2011). Probabilistic assessment of commercial design guides for steep reinforced slopes: implications for design. Proceedings of GeoRisk 2011: Geotechnical Risk Assessment and Management, Atlanta, Georgia, USA, June 2011, pp. 1055-1062.

Koerner, R.M. (2002). Beyond factor of safety: the probability of failure. Proceedings of the GRI16 Conference: Hot Topics in Geosynthetics - III, Philadelphia, Pennsylvania, USA, pp. 118.

Kulhawy, F.H. (1992). On the evaluation of static soil properties. Stability and Performance of Slopes and Embankments, ASCE Geotechnical Special Publication No. 31, pp. 95-115.

Lacasse, S., Nadim, F. (1996). Uncertainties in characterising soil properties. Uncertainty in the Geological Environment: From Theory to Practice, ASCE Geotechnical Special Publication No. 58 , pp. 49-75. 
653 654

655 656

657

658

659

660

661

662

663

664

665

666

667

668

669

670

671

672

673

674

675

676

677

678

679

680

Lee, I.K., White, W. \& Ingles, O.G. (1983). Geotechnical Engineering. Pitman, Boston, MA, USA, $508 \mathrm{p}$.

Leonards, G.A. (1975). Investigation of failures. Journal of the Geotechnical Engineering Division, ASCE, 108(GT2): 187-246.

Lopes, M.L., Moreira, S. \& Silvano, R. (2006). Database on geosynthetics short-term tensile strength. Internal Report, Faculty of Engineering, University of Porto, Portugal, June 2006, 10 p. (in Portuguese)

Low, B.K. \& Tang, W.H. (1997a). Reliability analysis of reinforced embankments on soft ground. Canadian Geotechnical Journal, 34: 672-685.

Low, B.K. \& Tang, W.H. (1997b). Efficient reliability evaluation using spreadsheet. Journal of Engineering Mechanics, 123(7): 749-752.

Lumb, P. (1974). Application of statistics in soil mechanics. $3^{\text {rd }}$ Chapter of Soil Mechanics - New Horizons. Butterworth and Company Publishers Limited, London, UK, pp. 44-111.

Malkawi, A.I., Hassan, W.F. \& Abdulla, F.A. (2000). Uncertainty and reliability analysis applied to slope stability. Structural Safety, 22: 161-187.

Modarres, M. (2006). Risk Analysis in Engineering: Techniques, Tools, and Trends. CRC Press, Taylor \& Francis Group, Florida, 424 p.

Morais, L.M. (2010). Scale effects associated with physical modelling of geocontainers. MSc Thesis, Faculty of Engineering, University of Porto, 120 p. (in Portuguese)

Oakley, J.E. \& O'Hagan, A. (2004). Probabilistic sensitivity analysis of complex models: a Bayesian approach. Journal of Royal Statistical Society B, 66(3): 751-769.

Phoon, K.-K. (2004). Towards reliability-based design for geotechnical engineering. Special lecture for Korean Geotechnical Society, Seoul, Korea, July 2004, 23 p.

Phoon, K.-K. \& Kulhawy, F.H. (1999). Characterization of geotechnical variability. Canadian Geotechnical Journal, 36: 612-624.

Phoon, K.-K., Kulhawy, F.H. \& Grigoriu, M.D. (1995). Reliability-based design of foundations for transmission line structures. Electric Power Research Institute, Report TR-105000, Palo Alto, California, USA. 
681

Pinho-Lopes, M. \& Lopes, M.L. (2013). Tensile properties of geosynthetics after installation damage. Environmental Geotechnics, 1(3): 161-178.

Rocscience Inc. (2010). Slide Version 6.0 - 2D Limit Equilibrium Slope Stability Analysis. www.rocscience.com, Toronto, Ontario, Canada.

Rubinstein, R.Y. (1981). Simulation and the Monte Carlo Method. John Wiley \& Sons, New York, USA, $372 \mathrm{p}$.

Sabatini, P.J., Griffin, L.M., Bonaparte, R., Espinoza, R.D. \& Giroud, J.P. (2002). Reliability of state of practice for selection of shear strength parameters for waste contaiment system stability analysis. Geotextiles and Geomembranes, 20(4): 241-262.

Saltelli, A., Chan, K. \& Scott, E.M. (2000). Sensitivity Analysis. John Wiley and Sons, New York, USA, $494 \mathrm{p}$.

Schreider, I.A. (1966). The Monte Carlo Method: The Method of Statistical Trials. Pergamon Press, New York, USA, $381 \mathrm{p}$.

Schultze, E. (1975). Some aspects concerning the application of statistics and probability to foundation structures. Proceedings of the Second International Conference on Applications of Statistics and Probability in Soil and Structural Engineering, Aachen, Germany, pp. 457494.

Sia, A.H. \& Dixon, N. (2007). Distribution and variability of interface shear strength and derived parameters. Geotextiles and Geomembranes, 25(3): 139-154.

Silvano, R.P. (2005). Geosynthetic-reinforced soil. Study of behaviour characterising parameters. MSc Thesis, Faculty of Science, University of Coimbra, 185 p. (in Portuguese)

Singh, A. (1971). How reliable is the factor of safety in foundation engineering? Proceedings of the First International Conference on Applications of Statistics and Probability in Soil and Structural Engineering, Hong Kong University Press, Hong Kong, pp. 389-424.

Sukmak, K., Sukmak, P., Horpibulsuk, S., Chinkulkijniwat, A., Arulrajah, A. \& Shen, S.-L. (2015). Pullout resistance of bearing reinforcement embedded in marginal lateritic soil at molding water contents. Geotextiles and Geomembranes (http://dx.doi.org/10.1016/j.geotexmem.2015.07.016). 
This manuscript is the accepted version of the paper:

Reliability analysis of geosynthetic-reinforced steep slopes, Geosynthetics International, Vol. 23, Issue 4, pp. 301 315, https://doi.org/10.1680/jgein.15.00057

709 Vieira, C.S. (2008). Geosynthetic-reinforced soil retaining walls and slopes. Seismic behaviour 710 and design methodologies. PhD Thesis, Faculty of Engineering, University of Porto, 575 p. 711 (in Portuguese)

712 Whitman, R.V. (2000). Organizing and Evaluating Uncertainty in Geotechnical Engineering. 713 Journal of Geotechnical and Geoenvironmental Engineering, 126(7): 583-593. 


\section{LIST OF TABLES}

Table 1. Relationship between $\beta$ and PF (modified from EC0; CEN (2002))

Table 2. Definition of Consequences Classes (modified from EC0; CEN (2002))

Table 3. Recommended minimum values for $\beta$ for ultimate limit states design (modified from EC0; CEN (2002))

Table 4. Typical coefficients of variation of design parameters

Table 5. Partial safety factors and coefficients of variation of the design parameters

Table 6. Design values, characteristic values and mean values of the design parameters

Table 7. Results of the probabilistic stability analysis of Slopes 1 to 9

Table 8. Coefficients of variation and surcharge limit values used in the probabilistic sensitivity analysis

Table 9. Sensitivity analysis of the COV of soil unit weight

Table 10. Sensitivity analysis of the COV of soil friction angle and soil-geogrid interface friction angle

Table 11. Sensitivity analysis of the COV of geogrid tensile strength

Table 12. Sensitivity analysis of the upper limit value of the surcharge load 
This manuscript is the accepted version of the paper:

Reliability analysis of geosynthetic-reinforced steep slopes, Geosynthetics International, Vol. 23, Issue 4, pp. 301 315, https://doi.org/10.1680/jgein.15.00057

Table 13. Sensitivity analysis for limit combinations 


\section{LIST OF FIGURES}

Figure 1. Schematic illustration of the geosynthetic-reinforced slopes

Figure 2. Global Minimum slip surface and over-design factor of Slope $1\left(\alpha=60^{\circ}, L=7.2 \mathrm{~m}\right.$, $\left.\phi_{d}=20^{\circ}, \gamma_{d}=23 \mathrm{kN} / \mathrm{m}^{3}\right)$

Figure 3. Global Minimum slip surface and over-design factor of Slope $2\left(\alpha=60^{\circ}, L=5.4 \mathrm{~m}\right.$, $\left.\phi_{d}=25^{\circ}, \gamma_{d}=23 \mathrm{kN} / \mathrm{m}^{3}\right)$

Figure 4. Global Minimum slip surface and over-design factor of Slope $3\left(\alpha=60^{\circ}, L=4.2 \mathrm{~m}\right.$, $\left.\phi_{d}=30^{\circ}, \gamma_{d}=23 \mathrm{kN} / \mathrm{m}^{3}\right)$

Figure 5. Global Minimum slip surface and over-design factor of Slope $4\left(\alpha=60^{\circ}, L=3.4 \mathrm{~m}\right.$, $\left.\phi_{d}=35^{\circ}, \gamma_{d}=23 \mathrm{kN} / \mathrm{m}^{3}\right)$

Figure 6. Global Minimum slip surface and over-design factor of Slope $5\left(\alpha=60^{\circ}, L=5.8 \mathrm{~m}\right.$, $\left.\phi_{d}=25^{\circ}, \gamma_{d}=23 \mathrm{kN} / \mathrm{m}^{3}\right)$

Figure 7. Global Minimum slip surface and over-design factor of Slope $6\left(\alpha=60^{\circ}, L=4.5 \mathrm{~m}\right.$, $\left.\phi_{d}=30^{\circ}, \gamma_{\mathrm{d}}=23 \mathrm{kN} / \mathrm{m}^{3}\right)$

Figure 8. Global Minimum slip surface and over-design factor of Slope $7\left(\alpha=60^{\circ}, L=3.6 \mathrm{~m}\right.$, $\left.\phi_{d}=35^{\circ}, \gamma_{d}=23 \mathrm{kN} / \mathrm{m}^{3}\right)$

Figure 9. Global Minimum slip surface and over-design factor of Slope 8 ( $\alpha=45^{\circ}, L=6.3 \mathrm{~m}$, $\left.\phi_{d}=25^{\circ}, \gamma_{d}=23 \mathrm{kN} / \mathrm{m}^{3}\right)$ 
Figure 10. Global Minimum slip surface and over-design factor of Slope $9\left(\alpha=75^{\circ}, L=5.8 \mathrm{~m}\right.$, $\left.\phi_{d}=25^{\circ}, \gamma_{d}=23 \mathrm{kN} / \mathrm{m}^{3}\right)$

Figure 11. Convergence of the reliability index of Slope 5 (Global Minimum and Overall Slope methods)

Figure 12. Comparison of results of the probabilistic stability analysis of Slope 5 obtained from the Global Minimum and Overall Slope methods: a) probability density function of the factor of safety; b) cumulative probability distribution of the factor of safety

Figure 13. Results of the probabilistic stability analysis of Slope 5: a) Global Minimum method;

b) Overall Slope method 
This manuscript is the accepted version of the paper:

Reliability analysis of geosynthetic-reinforced steep slopes, Geosynthetics International, Vol. 23, Issue 4, pp. 301 315, https://doi.org/10.1680/jgein.15.00057

\section{TABLES}


This manuscript is the accepted version of the paper:

Reliability analysis of geosynthetic-reinforced steep slopes, Geosynthetics International, Vol. 23, Issue 4, pp. 301 315, https://doi.org/10.1680/jgein.15.00057

Table 1. Relationship between $\beta$ and PF (modified from EC0; CEN (2002))

\begin{tabular}{|l|c|c|c|c|c|c|c|}
\hline PF & $10^{-1}$ & $10^{-2}$ & $10^{-3}$ & $10^{-4}$ & $10^{-5}$ & $10^{-6}$ & $10^{-7}$ \\
\hline$\beta$ & 1.28 & 2.32 & 3.09 & 3.72 & 4.27 & 4.75 & 5.20 \\
\hline
\end{tabular}


This manuscript is the accepted version of the paper:

Reliability analysis of geosynthetic-reinforced steep slopes, Geosynthetics International, Vol. 23, Issue 4, pp. 301315, https://doi.org/10.1680/jgein.15.00057

Table 2. Definition of Consequences Classes (modified from EC0; CEN (2002))

\begin{tabular}{|l|c|c|}
\hline \multirow{2}{*}{$\begin{array}{l}\text { Consequences } \\
\text { Class }\end{array}$} & \multicolumn{2}{|c|}{ Consequence } \\
\cline { 2 - 3 } & Loss of human life & $\begin{array}{c}\text { Social, economic and } \\
\text { environmental }\end{array}$ \\
\hline CC1 & Low & Small/Negligible \\
CC2 & Medium & Considerable \\
CC3 & High & Very great \\
\hline
\end{tabular}


This manuscript is the accepted version of the paper:

Reliability analysis of geosynthetic-reinforced steep slopes, Geosynthetics International, Vol. 23, Issue 4, pp. 301 315, https://doi.org/10.1680/jgein.15.00057

Table 3. Recommended minimum values for $\beta$ for ultimate limit states design (modified from EC0; CEN (2002))

\begin{tabular}{|l|c|c|}
\hline \multirow{2}{*}{$\begin{array}{l}\text { Reliability } \\
\text { Class }\end{array}$} & \multicolumn{2}{|c|}{ Minimum values for $\beta$} \\
\cline { 2 - 3 } & $\begin{array}{c}\text { 1 year reference } \\
\text { period }\end{array}$ & $\begin{array}{c}50 \text { years reference } \\
\text { period }\end{array}$ \\
\hline RC1 & 4.2 & 3.3 \\
RC2 & 4.7 & 3.8 \\
RC3 & 5.2 & 4.3 \\
\hline
\end{tabular}


This manuscript is the accepted version of the paper:

Reliability analysis of geosynthetic-reinforced steep slopes, Geosynthetics International, Vol. 23, Issue 4, pp. 301 -

315, https://doi.org/10.1680/jgein.15.00057

Table 4. Typical coefficients of variation of design parameters

\begin{tabular}{|c|c|c|}
\hline Parameter & COV (\%) & Source \\
\hline Soil unit weight & $3-7$ & Harr (1984), Kulhawy (1992) \\
\hline $\begin{array}{l}\text { Soil friction angle } \\
\text { (granular soil) }\end{array}$ & $2-15$ & $\begin{array}{l}\text { Singh (1971), Lumb (1974), Hoeg and Murarka (1974), Schultze } \\
\text { (1975), Harr (1984), Kulhawy (1992), Phoon et al. (1995) }\end{array}$ \\
\hline $\begin{array}{l}\text { Soil-geosynthetic } \\
\text { interface friction angle }\end{array}$ & $\begin{aligned} 3.7 & -5.4^{1} \\
10.2 & -16.7^{2}\end{aligned}$ & Sia and Dixon (2007) \\
\hline $\begin{array}{l}\text { Geosynthetic tensile } \\
\text { strength }^{3}\end{array}$ & $1.4-6.8$ & $\begin{array}{c}\text { Silvano (2005), Lopes et al. (2006), Vieira (2008), Morais (2010), } \\
\text { Pinho-Lopes and Lopes (2013) }\end{array}$ \\
\hline
\end{tabular}

1Values corresponding to coarse grained soil-geosynthetic interfaces.

${ }^{2}$ Values corresponding to fine grained soil-geosynthetic interfaces.

${ }^{3}$ Based on repeatability testing programmes. 
This manuscript is the accepted version of the paper:

Reliability analysis of geosynthetic-reinforced steep slopes, Geosynthetics International, Vol. 23, Issue 4, pp. 301 315, https://doi.org/10.1680/jgein.15.00057

Table 5. Partial safety factors and coefficients of variation of the design parameters

\begin{tabular}{|l|c|c|}
\hline Parameter & PSF & COV (\%) \\
\hline Soil unit weight & 1 & 5 \\
Soil friction angle & $1.25^{1}$ & 7 \\
Soil-geogrid interface friction angle & $1.25^{1}$ & 7 \\
Long-term tensile strength of the geogrids & 1.25 & 5 \\
Surcharge load & 1.3 & - \\
\hline
\end{tabular}

${ }^{1}$ Applied to the tangent of the friction angle. 
Table 6. Design values, characteristic values and mean values of the design parameters

\begin{tabular}{|c|c|c|c|c|}
\hline & Parameter & DV & $\mathrm{CHV}$ & MV \\
\hline \multirow{5}{*}{$\begin{array}{c}\text { Slope } 1 \\
\alpha=60^{\circ} \\
L=7.2 \mathrm{~m}\end{array}$} & Soil unit weight $\left(\mathrm{kN} / \mathrm{m}^{3}\right)$ & 23.0 & 23.0 & 21.3 \\
\hline & Soil friction angle $\left(^{\circ}\right)$ & 20.0 & 24.5 & 27.6 \\
\hline & Soil-geogrid interface friction angle $\left(^{\circ}\right)$ & 17.1 & 21.0 & 23.8 \\
\hline & Geogrid tensile strength - GGR1 (kN/m) & 34.6 & 43.3 & 47.1 \\
\hline & Geogrid tensile strength - GGR2 (kN/m) & 19.8 & 24.8 & 27.0 \\
\hline \multirow{5}{*}{$\begin{array}{l}\text { Slope } 2 \\
\alpha=60^{\circ} \\
L=5.4 \mathrm{~m}\end{array}$} & Soil unit weight $\left(\mathrm{kN} / \mathrm{m}^{3}\right)$ & 23.0 & 23.0 & 21.3 \\
\hline & Soil friction angle $\left(^{\circ}\right)$ & 25.0 & 30.2 & 34.2 \\
\hline & Soil-geogrid interface friction angle $\left(^{\circ}\right)$ & 21.4 & 26.1 & 29.5 \\
\hline & Geogrid tensile strength - GGR1 (kN/m) & 24.7 & 30.9 & 33.6 \\
\hline & Geogrid tensile strength - GGR2 (kN/m) & 14.1 & 17.6 & 19.2 \\
\hline \multirow{5}{*}{$\begin{array}{c}\text { Slope } 3 \\
\alpha=60^{\circ} \\
L=4.2 \mathrm{~m}\end{array}$} & Soil unit weight $\left(\mathrm{kN} / \mathrm{m}^{3}\right)$ & 23.0 & 23.0 & 21.3 \\
\hline & Soil friction angle $\left(^{\circ}\right)$ & 30.0 & 35.8 & 40.5 \\
\hline & Soil-geogrid interface friction angle $\left(^{\circ}\right)$ & 25.7 & 31.0 & 35.1 \\
\hline & Geogrid tensile strength - GGR1 (kN/m) & 17.3 & 21.6 & 23.6 \\
\hline & Geogrid tensile strength - GGR2 (kN/m) & 9.9 & 12.4 & 13.5 \\
\hline \multirow{5}{*}{$\begin{array}{c}\text { Slope } 4 \\
\alpha=60^{\circ} \\
L=3.4 \mathrm{~m}\end{array}$} & Soil unit weight $\left(\mathrm{kN} / \mathrm{m}^{3}\right)$ & 23.0 & 23.0 & 21.3 \\
\hline & Soil friction angle $\left(^{\circ}\right)$ & 35.0 & 41.2 & 46.6 \\
\hline & Soil-geogrid interface friction angle $\left(^{\circ}\right)$ & 30.0 & 35.8 & 40.5 \\
\hline & Geogrid tensile strength - GGR1 (kN/m) & 11.7 & 14.6 & 15.9 \\
\hline & Geogrid tensile strength - GGR2 (kN/m) & 9.0 & 11.3 & 12.3 \\
\hline \multirow{6}{*}{$\begin{array}{c}\text { Slope } 5 \\
\alpha=60^{\circ} \\
L=5.8 \mathrm{~m}\end{array}$} & Soil unit weight $\left(\mathrm{kN} / \mathrm{m}^{3}\right)$ & 23.0 & 23.0 & 21.3 \\
\hline & Soil friction angle $\left(^{\circ}\right)$ & 25.0 & 30.2 & 34.2 \\
\hline & Soil-geogrid interface friction angle $\left(^{\circ}\right)$ & 21.4 & 26.1 & 29.5 \\
\hline & Geogrid tensile strength - GGR1 (kN/m) & 26.3 & 32.9 & 35.8 \\
\hline & Geogrid tensile strength - GGR2 (kN/m) & 15.7 & 19.6 & 21.4 \\
\hline & Surcharge load $(\mathrm{kPa})$ & 13.0 & 10.0 & 10.0 \\
\hline \multirow{6}{*}{$\begin{array}{c}\text { Slope } 6 \\
\alpha=60^{\circ} \\
L=4.5 \mathrm{~m}\end{array}$} & Soil unit weight $\left(\mathrm{kN} / \mathrm{m}^{3}\right)$ & 23.0 & 23.0 & 21.3 \\
\hline & Soil friction angle $\left(^{\circ}\right)$ & 30.0 & 35.8 & 40.5 \\
\hline & Soil-geogrid interface friction angle $\left(^{\circ}\right)$ & 25.7 & 31.0 & 35.1 \\
\hline & Geogrid tensile strength - GGR1 (kN/m) & 18.5 & 23.1 & 25.2 \\
\hline & Geogrid tensile strength - GGR2 (kN/m) & 11.1 & 13.9 & 15.1 \\
\hline & Surcharge load $(\mathrm{kPa})$ & 13.0 & 10.0 & 10.0 \\
\hline \multirow{6}{*}{$\begin{array}{c}\text { Slope } 7 \\
\alpha=60^{\circ} \\
L=3.6 \mathrm{~m}\end{array}$} & Soil unit weight $\left(\mathrm{kN} / \mathrm{m}^{3}\right)$ & 23.0 & 23.0 & 21.3 \\
\hline & Soil friction angle $\left(^{\circ}\right)$ & 35.0 & 41.2 & 46.6 \\
\hline & Soil-geogrid interface friction angle $\left(^{\circ}\right)$ & 30.0 & 35.8 & 40.5 \\
\hline & Geogrid tensile strength - GGR1 (kN/m) & 12.5 & 15.6 & 17.0 \\
\hline & Geogrid tensile strength - GGR2 (kN/m) & 10.0 & 12.5 & 13.6 \\
\hline & Surcharge load $(\mathrm{kPa})$ & 13.0 & 10.0 & 10.0 \\
\hline \multirow{6}{*}{$\begin{array}{c}\text { Slope } 8 \\
\alpha=45^{\circ} \\
L=6.3 \mathrm{~m}\end{array}$} & Soil unit weight $\left(\mathrm{kN} / \mathrm{m}^{3}\right)$ & 23.0 & 23.0 & 21.3 \\
\hline & Soil friction angle $\left(^{\circ}\right)$ & 25.0 & 30.2 & 34.2 \\
\hline & Soil-geogrid interface friction angle $\left(^{\circ}\right)$ & 21.4 & 26.1 & 29.5 \\
\hline & Geogrid tensile strength - GGR1 (kN/m) & 17.1 & 21.4 & 23.3 \\
\hline & Geogrid tensile strength - GGR2 (kN/m) & 10.3 & 12.9 & 14.0 \\
\hline & Surcharge load $(\mathrm{kPa})$ & 13.0 & 10.0 & 10.0 \\
\hline \multirow{6}{*}{$\begin{array}{l}\text { Slope } 9 \\
\alpha=75^{\circ} \\
L=5.8 \mathrm{~m}\end{array}$} & Soil unit weight $\left(\mathrm{kN} / \mathrm{m}^{3}\right)$ & 23.0 & 23.0 & 21.3 \\
\hline & Soil friction angle $\left(^{\circ}\right)$ & 25.0 & 30.2 & 34.2 \\
\hline & Soil-geogrid interface friction angle $\left(^{\circ}\right)$ & 21.4 & 26.1 & 29.5 \\
\hline & Geogrid tensile strength - GGR1 (kN/m) & 36.3 & 45.4 & 49.4 \\
\hline & Geogrid tensile strength - GGR2 (kN/m) & 21.7 & 27.1 & 29.6 \\
\hline & Surcharge load $(\mathrm{kPa})$ & 13.0 & 10.0 & 10.0 \\
\hline
\end{tabular}


Table 7. Results of the probabilistic stability analysis of Slopes 1 to 9

\begin{tabular}{|c|c|ccc|ccc|}
\cline { 2 - 7 } \multicolumn{1}{c|}{} & \multirow{2}{*}{\begin{tabular}{c} 
FS \\
\cline { 2 - 8 }
\end{tabular}} & \multicolumn{2}{c|}{ Global Minimum $(n=1000000)$} & \multicolumn{3}{c|}{ Overall Slope $(n=1000000)$} \\
\hline Slope 1 & 1.450 & 1.453 & 0 & 4.344 & 1.449 & 0 & 4.464 \\
Slope 2 & 1.462 & 1.466 & 0 & 4.228 & 1.461 & 0 & 4.167 \\
Slope 3 & 1.487 & 1.492 & 0 & 3.827 & 1.492 & 0 & 3.901 \\
Slope 4 & 1.533 & 1.542 & 0 & 3.631 & 1.543 & 0 & 3.641 \\
Slope 5 & 1.476 & 1.489 & 0 & 4.141 & 1.489 & 0 & 4.130 \\
Slope 6 & 1.506 & 1.519 & 0 & 3.838 & 1.516 & 0 & 3.893 \\
Slope 7 & 1.542 & 1.559 & 0 & 3.618 & 1.558 & 0 & 3.639 \\
Slope 8 & 1.475 & 1.487 & 0 & 3.852 & 1.485 & 0 & 3.847 \\
Slope 9 & 1.484 & 1.497 & 0 & 4.587 & 1.498 & 0 & 4.591 \\
\hline
\end{tabular}

${ }^{1}$ Determined as the ratio of the number of simulations with $\mathrm{FS}<1$ to the total number of simulations $(n=1000000)$. 
This manuscript is the accepted version of the paper:

Reliability analysis of geosynthetic-reinforced steep slopes, Geosynthetics International, Vol. 23, Issue 4, pp. 301 315, https://doi.org/10.1680/jgein.15.00057

Table 8. Coefficients of variation and surcharge limit values used in the probabilistic sensitivity analysis

\begin{tabular}{|c|c|c|c|c|}
\hline \multicolumn{4}{|c|}{ COV (\%) } & Limits $(\mathrm{kPa})$ \\
\hline$\gamma$ & $\phi$ & $\delta$ & $T$ & $S$ \\
\hline 1 & 2 & 2 & 1 & $0-15$ \\
\hline 3 & 5 & 5 & 3 & $0-30$ \\
\hline 5 & 7 & 7 & 5 & $0-50$ \\
\hline 7 & 10 & 10 & 7 & - \\
\hline 10 & 15 & 15 & 10 & - \\
\hline
\end{tabular}


This manuscript is the accepted version of the paper:

Reliability analysis of geosynthetic-reinforced steep slopes, Geosynthetics International, Vol. 23, Issue 4, pp. 301 315, https://doi.org/10.1680/jgein.15.00057

Table 9. Sensitivity analysis of the COV of soil unit weight

\begin{tabular}{|c|c|c|c|c|c|c|c|}
\cline { 2 - 8 } \multicolumn{1}{c|}{} & \multicolumn{3}{c|}{ COV (\%) } & Limits (kPa) & \multicolumn{3}{c|}{ Results } \\
\cline { 2 - 8 } Slope 5 & $\gamma$ & $\phi / \delta$ & $T$ & $S$ & FS (mean) & PF (\%) & $\beta$ \\
\hline \multirow{5}{*}{ Slope 6 } & 1 & 7 & 5 & $0-30$ & 1.489 & 0 & 4.153 \\
& 3 & 7 & 5 & $0-30$ & 1.489 & 0 & 4.148 \\
& 5 & 7 & 5 & $0-30$ & 1.489 & 0 & 4.141 \\
& 7 & 7 & 5 & $0-30$ & 1.490 & 0 & 4.125 \\
& 10 & 7 & 5 & $0-30$ & 1.491 & 0 & 4.094 \\
\hline \multirow{5}{*}{ Slope 8 } & 1 & 7 & 5 & $0-30$ & 1.519 & 0 & 3.847 \\
& 3 & 7 & 5 & $0-30$ & 1.519 & 0 & 3.844 \\
& 7 & 7 & 5 & $0-30$ & 1.519 & 0 & 3.838 \\
& 10 & 7 & 5 & $0-30$ & 1.519 & 0 & 3.832 \\
& 1 & 7 & 5 & $0-30$ & 1.487 & 0 & 3.853 \\
& 3 & 7 & 5 & $0-30$ & 1.487 & 0 & 3.853 \\
& 5 & 7 & 5 & $0-30$ & 1.487 & 0 & 3.852 \\
& 7 & 7 & 5 & $0-30$ & 1.487 & 0 & 3.851 \\
& 10 & 7 & 5 & $0-30$ & 1.488 & 0 & 3.845 \\
\hline \multirow{5}{*}{ Slope 9 } & 1 & 7 & 5 & $0-30$ & 1.497 & 0 & 4.640 \\
& 3 & 7 & 5 & $0-30$ & 1.497 & 0 & 4.624 \\
& 7 & 7 & 5 & $0-30$ & 1.497 & 0 & 4.587 \\
& 10 & 7 & 5 & $0-30$ & 1.498 & 0 & 4.534 \\
& & & & $5-30$ & 1.500 & 0 & 4.426 \\
\hline
\end{tabular}


This manuscript is the accepted version of the paper:

Reliability analysis of geosynthetic-reinforced steep slopes, Geosynthetics International, Vol. 23, Issue 4, pp. 301 315, https://doi.org/10.1680/jgein.15.00057

Table 10. Sensitivity analysis of the COV of soil friction angle and soil-geogrid interface friction angle

\begin{tabular}{|c|c|c|c|c|c|c|c|}
\hline & \multicolumn{3}{|c|}{$\operatorname{cov}(\%)$} & \multirow{2}{*}{$\begin{array}{c}\text { Limits }(\mathrm{kPa}) \\
S\end{array}$} & \multicolumn{3}{|c|}{ Results } \\
\hline & $\gamma$ & $\phi / \delta$ & $T$ & & FS (mean) & PF (\%) & $\beta$ \\
\hline \multirow{5}{*}{ Slope 5} & 5 & 2 & 5 & $0-30$ & 1.486 & 0 & 10.036 \\
\hline & 5 & 5 & 5 & $0-30$ & 1.488 & 0 & 5.537 \\
\hline & 5 & 7 & 5 & $0-30$ & 1.489 & 0 & 4.141 \\
\hline & 5 & 10 & 5 & $0-30$ & 1.493 & 0.0045 & 2.978 \\
\hline & 5 & 15 & 5 & $0-30$ & 1.501 & 1.2325 & 2.021 \\
\hline \multirow{5}{*}{ Slope 6} & 5 & 2 & 5 & $0-30$ & 1.514 & 0 & 10.439 \\
\hline & 5 & 5 & 5 & $0-30$ & 1.516 & 0 & 5.228 \\
\hline & 5 & 7 & 5 & $0-30$ & 1.519 & 0 & 3.838 \\
\hline & 5 & 10 & 5 & $0-30$ & 1.525 & 0.0085 & 2.732 \\
\hline & 5 & 15 & 5 & $0-30$ & 1.539 & 1.6232 & 1.841 \\
\hline \multirow{5}{*}{ Slope 8} & 5 & 2 & 5 & $0-30$ & 1.484 & 0 & 10.195 \\
\hline & 5 & 5 & 5 & $0-30$ & 1.485 & 0 & 5.220 \\
\hline & 5 & 7 & 5 & $0-30$ & 1.487 & 0 & 3.852 \\
\hline & 5 & 10 & 5 & $0-30$ & 1.491 & 0.0275 & 2.751 \\
\hline & 5 & 15 & 5 & $0-30$ & 1.500 & 2.0566 & 1.863 \\
\hline \multirow{5}{*}{ Slope 9} & 5 & 2 & 5 & $0-30$ & 1.495 & 0 & 9.657 \\
\hline & 5 & 5 & 5 & $0-30$ & 1.496 & 0 & 5.983 \\
\hline & 5 & 7 & 5 & $0-30$ & 1.497 & 0 & 4.587 \\
\hline & 5 & 10 & 5 & $0-30$ & 1.500 & 0.0001 & 3.351 \\
\hline & 5 & 15 & 5 & $0-30$ & 1.507 & 0.4336 & 2.292 \\
\hline
\end{tabular}


This manuscript is the accepted version of the paper:

Reliability analysis of geosynthetic-reinforced steep slopes, Geosynthetics International, Vol. 23, Issue 4, pp. 301 315, https://doi.org/10.1680/jgein.15.00057

Table 11. Sensitivity analysis of the COV of geogrid tensile strength

\begin{tabular}{|c|c|c|c|c|c|c|c|}
\hline & \multicolumn{3}{|c|}{ COV (\%) } & Limits $(\mathrm{kPa})$ & \multicolumn{3}{|c|}{ Results } \\
\hline & $\gamma$ & $\phi / \delta$ & $T$ & $s$ & FS (mean) & PF (\%) & $\beta$ \\
\hline \multirow{5}{*}{ Slope 5} & 5 & 7 & 1 & $0-30$ & 1.489 & 0 & 4.157 \\
\hline & 5 & 7 & 3 & $0-30$ & 1.489 & 0 & 4.150 \\
\hline & 5 & 7 & 5 & $0-30$ & 1.489 & 0 & 4.141 \\
\hline & 5 & 7 & 7 & $0-30$ & 1.489 & 0 & 4.122 \\
\hline & 5 & 7 & 10 & $0-30$ & 1.489 & 0 & 4.086 \\
\hline \multirow{5}{*}{ Slope 6} & 5 & 7 & 1 & $0-30$ & 1.519 & 0 & 3.849 \\
\hline & 5 & 7 & 3 & $0-30$ & 1.519 & 0 & 3.846 \\
\hline & 5 & 7 & 5 & $0-30$ & 1.519 & 0 & 3.838 \\
\hline & 5 & 7 & 7 & $0-30$ & 1.519 & 0 & 3.830 \\
\hline & 5 & 7 & 10 & $0-30$ & 1.519 & 0 & 3.810 \\
\hline \multirow{5}{*}{ Slope 8} & 5 & 7 & 1 & $0-30$ & 1.487 & 0 & 3.855 \\
\hline & 5 & 7 & 3 & $0-30$ & 1.487 & 0 & 3.852 \\
\hline & 5 & 7 & 5 & $0-30$ & 1.487 & 0 & 3.852 \\
\hline & 5 & 7 & 7 & $0-30$ & 1.487 & 0 & 3.849 \\
\hline & 5 & 7 & 10 & $0-30$ & 1.487 & 0 & 3.842 \\
\hline \multirow{5}{*}{ Slope 9} & 5 & 7 & 1 & $0-30$ & 1.498 & 0 & 4.651 \\
\hline & 5 & 7 & 3 & $0-30$ & 1.498 & 0 & 4.629 \\
\hline & 5 & 7 & 5 & $0-30$ & 1.497 & 0 & 4.587 \\
\hline & 5 & 7 & 7 & $0-30$ & 1.497 & 0 & 4.527 \\
\hline & 5 & 7 & 10 & $0-30$ & 1.497 & 0 & 4.402 \\
\hline
\end{tabular}


This manuscript is the accepted version of the paper:

Reliability analysis of geosynthetic-reinforced steep slopes, Geosynthetics International, Vol. 23, Issue 4, pp. 301 315, https://doi.org/10.1680/jgein.15.00057

Table 12. Sensitivity analysis of the upper limit value of the surcharge load

\begin{tabular}{|c|c|c|c|c|c|c|c|}
\cline { 2 - 8 } \multicolumn{1}{c|}{} & \multicolumn{3}{c|}{ COV (\%) } & Limits (kPa) & \multicolumn{3}{c|}{ Results } \\
\cline { 2 - 8 } Slope 5 & $\gamma$ & $\phi / \delta$ & $T$ & $S$ & FS (mean) & PF $(\%)$ & $\beta$ \\
& 5 & 7 & 5 & $0-15$ & 1.502 & 0 & 4.321 \\
& 5 & 7 & 5 & $0-30$ & 1.489 & 0 & 4.141 \\
Slope 6 & 5 & 7 & 5 & $0-15$ & 1.530 & 0 & 3.958 \\
& 5 & 7 & 5 & $0-30$ & 1.519 & 0 & 3.838 \\
& 5 & 7 & 5 & $0-50$ & 1.514 & 0 & 3.767 \\
\hline \multirow{3}{*}{ Slope 8 } & 5 & 7 & 5 & $0-15$ & 1.499 & 0 & 3.993 \\
& 5 & 7 & 5 & $0-30$ & 1.487 & 0 & 3.852 \\
& 5 & 7 & 5 & $0-50$ & 1.482 & 0 & 3.766 \\
\hline \multirow{3}{*}{ Slope 9 } & 5 & 7 & 5 & $0-15$ & 1.510 & 0 & 4.828 \\
& 5 & 7 & 5 & $0-30$ & 1.497 & 0 & 4.587 \\
& 5 & 7 & 5 & $0-50$ & 1.492 & 0 & 4.447 \\
\hline
\end{tabular}


This manuscript is the accepted version of the paper:

Reliability analysis of geosynthetic-reinforced steep slopes, Geosynthetics International, Vol. 23, Issue 4, pp. 301 315, https://doi.org/10.1680/jgein.15.00057

Table 13. Sensitivity analysis for limit combinations

\begin{tabular}{|c|c|c|c|c|c|c|c|}
\cline { 2 - 8 } \multicolumn{1}{c|}{} & \multicolumn{3}{c|}{ COV (\%) } & Limits (kPa) & \multicolumn{3}{c|}{ Results } \\
\cline { 2 - 8 } \multicolumn{1}{c|}{} & $\gamma$ & $\phi / \delta$ & $T$ & $S$ & FS (mean) & PF (\%) & $\beta$ \\
\hline \multirow{2}{*}{ Slope 5 } & 1 & 2 & 1 & $0-15$ & 1.498 & 0 & 13.009 \\
& 10 & 15 & 10 & $0-50$ & 1.497 & 1.3748 & 1.991 \\
\hline \multirow{2}{*}{ Slope 6 } & 1 & 2 & 1 & $0-15$ & 1.525 & 0 & 12.689 \\
& 10 & 15 & 10 & $0-50$ & 1.536 & 1.7600 & 1.823 \\
\hline \multirow{2}{*}{ Slope 8 } & 1 & 2 & 1 & $0-15$ & 1.495 & 0 & 12.342 \\
& 10 & 15 & 10 & $0-50$ & 1.496 & 2.1754 & 1.843 \\
\hline \multirow{2}{*}{ Slope 9 } & 1 & 2 & 1 & $0-15$ & 1.507 & 0 & 14.047 \\
& 10 & 15 & 10 & $0-50$ & 1.504 & 0.6034 & 2.227 \\
\hline
\end{tabular}


This manuscript is the accepted version of the paper:

Reliability analysis of geosynthetic-reinforced steep slopes, Geosynthetics International, Vol. 23, Issue 4, pp. 301 315, https://doi.org/10.1680/jgein.15.00057

\section{FIGURES}


Reliability analysis of geosynthetic-reinforced steep slopes, Geosynthetics International, Vol. 23, Issue 4, pp. 301 315, https://doi.org/10.1680/jgein.15.00057

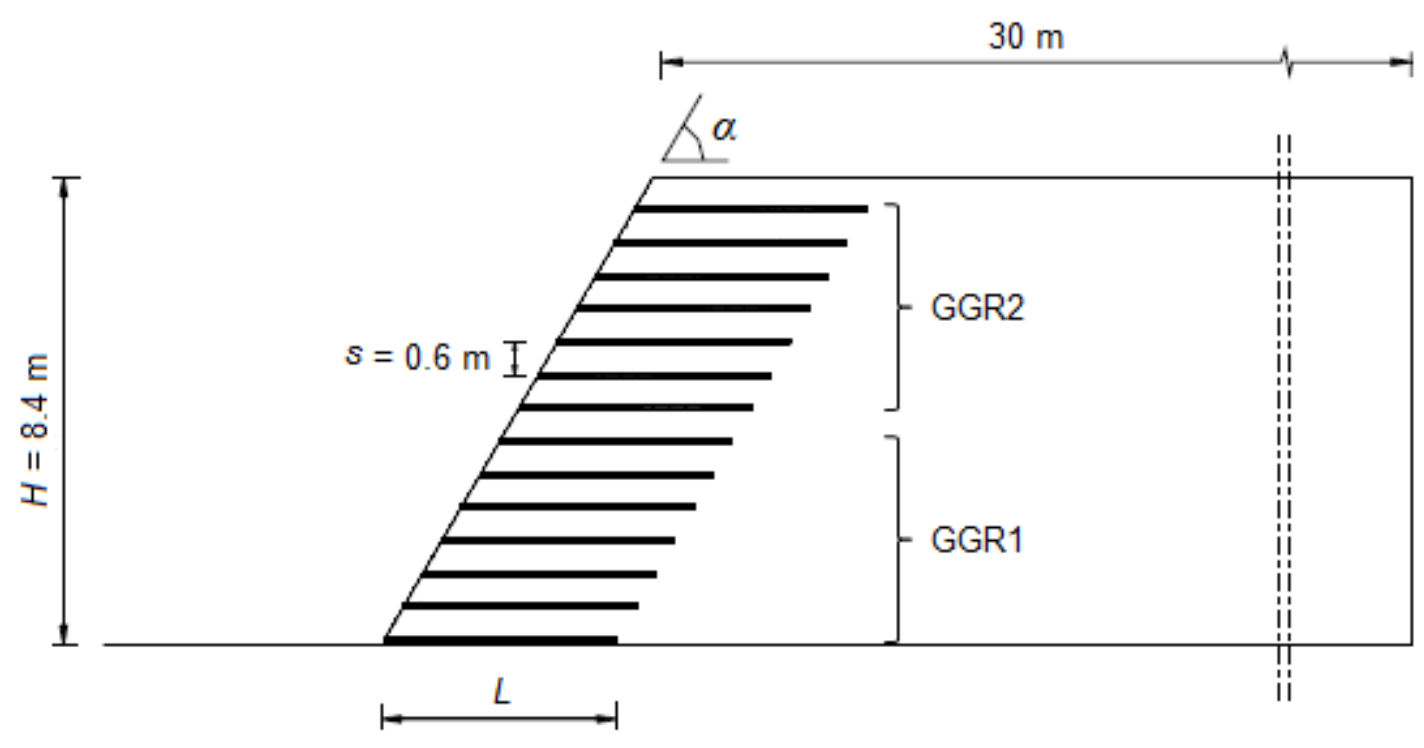

Figure 1. Schematic illustration of the geosynthetic-reinforced slopes 
This manuscript is the accepted version of the paper:

Reliability analysis of geosynthetic-reinforced steep slopes, Geosynthetics International, Vol. 23, Issue 4, pp. 301 315, https://doi.org/10.1680/jgein.15.00057

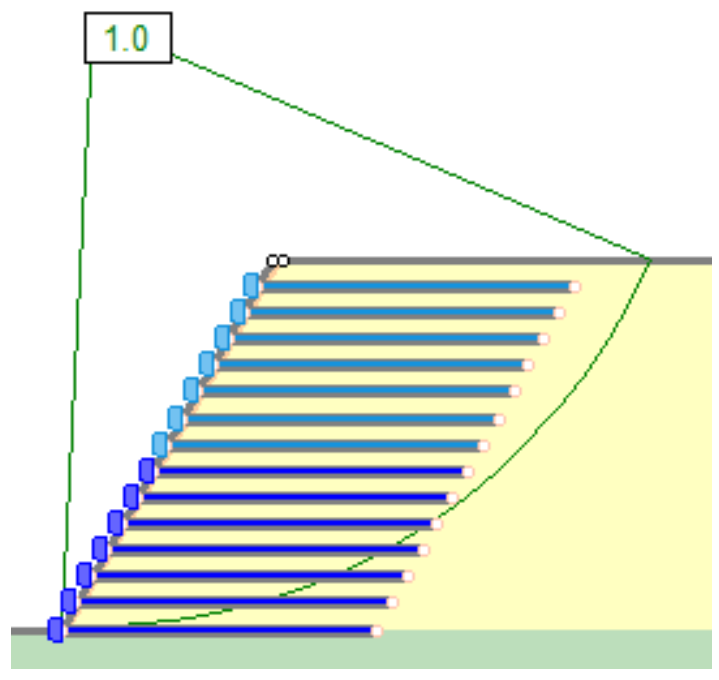

Figure 2. Global Minimum slip surface and over-design factor of Slope $1\left(\alpha=60^{\circ}, L=7.2 \mathrm{~m}\right.$, $\left.\phi_{d}=20^{\circ}, \gamma_{d}=23 \mathrm{kN} / \mathrm{m}^{3}\right)$ 
This manuscript is the accepted version of the paper:

Reliability analysis of geosynthetic-reinforced steep slopes, Geosynthetics International, Vol. 23, Issue 4, pp. 301 315, https://doi.org/10.1680/jgein.15.00057

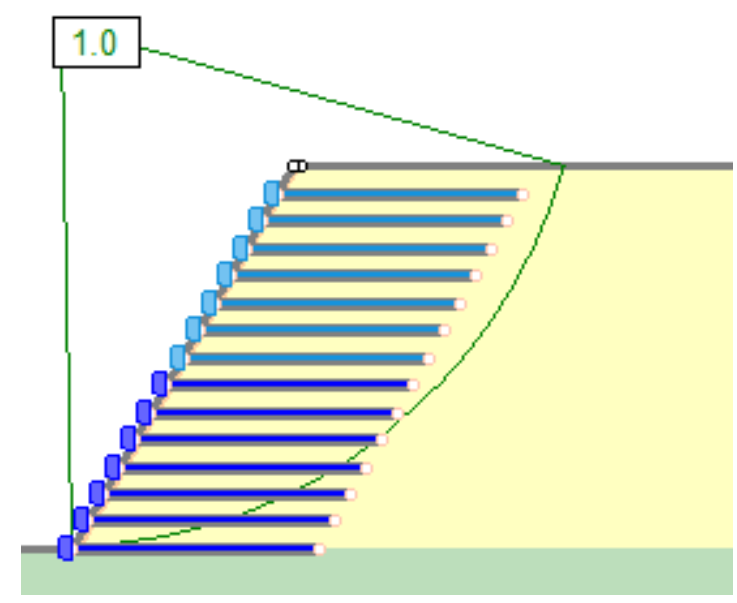

Figure 3. Global Minimum slip surface and over-design factor of Slope $2\left(\alpha=60^{\circ}, L=5.4 \mathrm{~m}\right.$, $\left.\phi_{d}=25^{\circ}, \gamma_{d}=23 \mathrm{kN} / \mathrm{m}^{3}\right)$ 
This manuscript is the accepted version of the paper:

Reliability analysis of geosynthetic-reinforced steep slopes, Geosynthetics International, Vol. 23, Issue 4, pp. 301 315, https://doi.org/10.1680/jgein.15.00057

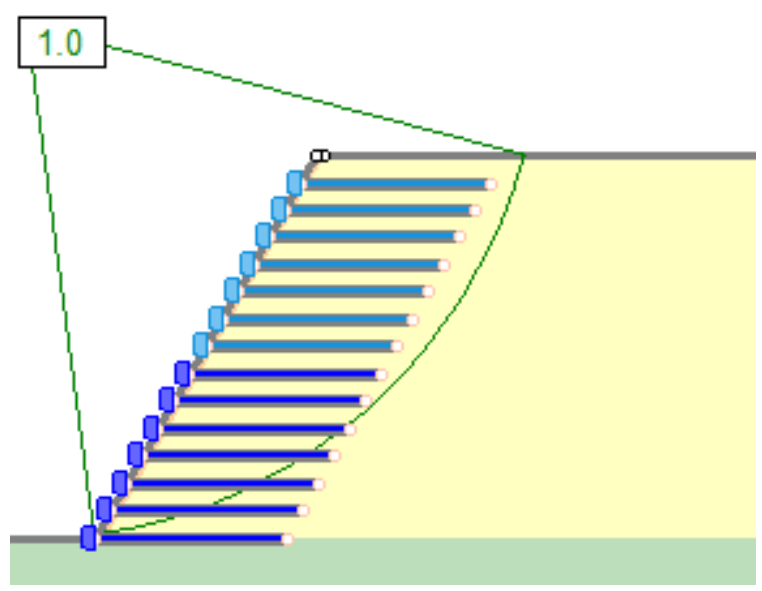

Figure 4. Global Minimum slip surface and over-design factor of Slope $3\left(\alpha=60^{\circ}, L=4.2 \mathrm{~m}\right.$, $\left.\phi_{d}=30^{\circ}, \gamma_{\mathrm{d}}=23 \mathrm{kN} / \mathrm{m}^{3}\right)$ 
This manuscript is the accepted version of the paper:

Reliability analysis of geosynthetic-reinforced steep slopes, Geosynthetics International, Vol. 23, Issue 4, pp. 301 315, https://doi.org/10.1680/jgein.15.00057

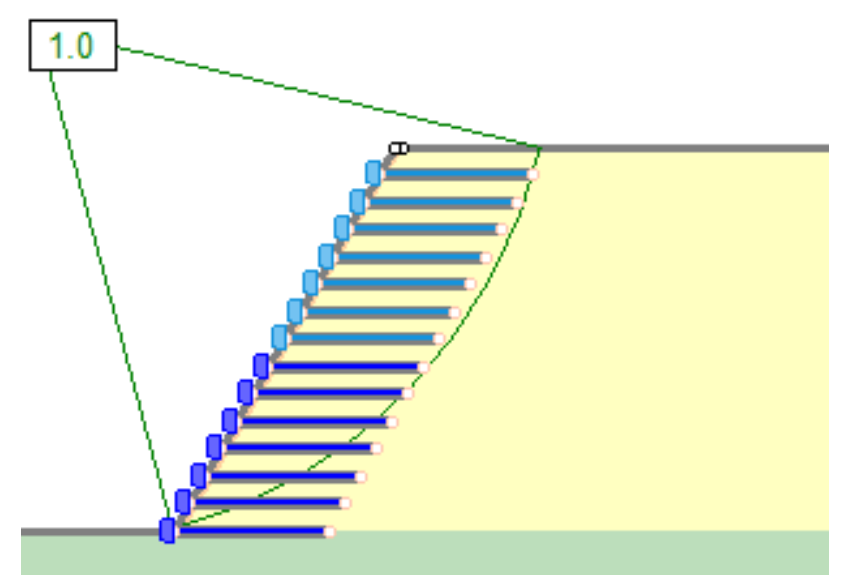

Figure 5. Global Minimum slip surface and over-design factor of Slope $4\left(\alpha=60^{\circ}, L=3.4 \mathrm{~m}\right.$, $\left.\phi_{d}=35^{\circ}, \gamma_{d}=23 \mathrm{kN} / \mathrm{m}^{3}\right)$ 
This manuscript is the accepted version of the paper:

Reliability analysis of geosynthetic-reinforced steep slopes, Geosynthetics International, Vol. 23, Issue 4, pp. 301 315, https://doi.org/10.1680/jgein.15.00057

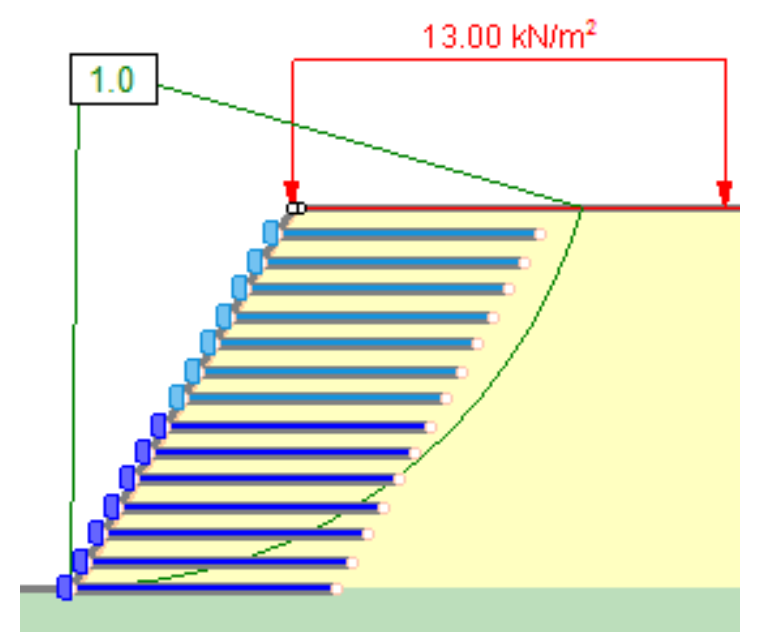

Figure 6. Global Minimum slip surface and over-design factor of Slope $5\left(\alpha=60^{\circ}, L=5.8 \mathrm{~m}\right.$, $\left.\phi_{d}=25^{\circ}, \gamma_{d}=23 \mathrm{kN} / \mathrm{m}^{3}\right)$ 
This manuscript is the accepted version of the paper:

Reliability analysis of geosynthetic-reinforced steep slopes, Geosynthetics International, Vol. 23, Issue 4, pp. 301 315, https://doi.org/10.1680/jgein.15.00057

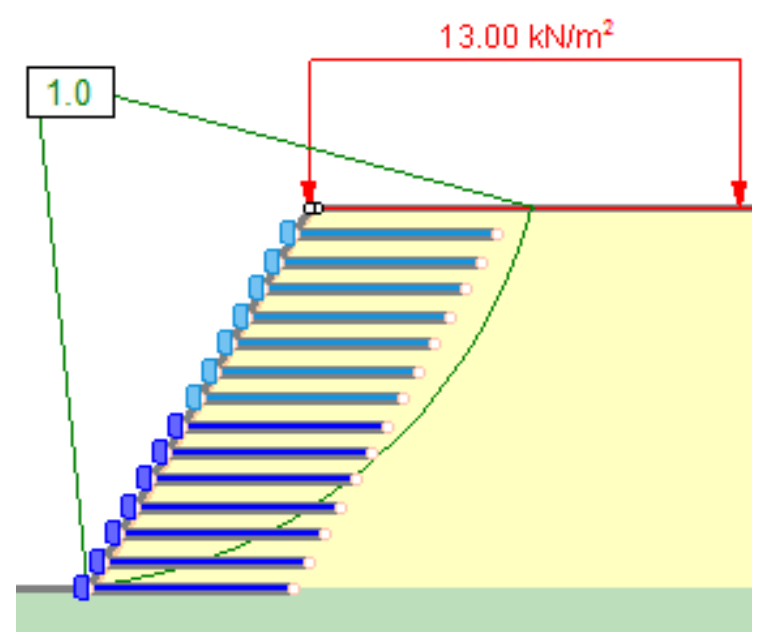

Figure 7. Global Minimum slip surface and over-design factor of Slope $6\left(\alpha=60^{\circ}, L=4.5 \mathrm{~m}\right.$, $\left.\phi_{d}=30^{\circ}, \gamma_{d}=23 \mathrm{kN} / \mathrm{m}^{3}\right)$ 
This manuscript is the accepted version of the paper:

Reliability analysis of geosynthetic-reinforced steep slopes, Geosynthetics International, Vol. 23, Issue 4, pp. 301 315, https://doi.org/10.1680/jgein.15.00057

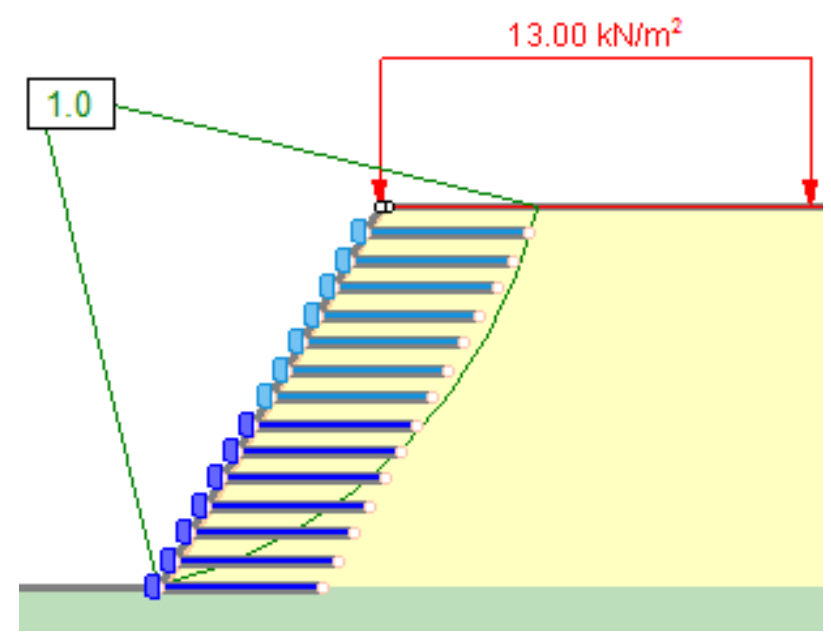

Figure 8. Global Minimum slip surface and over-design factor of Slope $7\left(\alpha=60^{\circ}, L=3.6 \mathrm{~m}\right.$, $\left.\phi_{d}=35^{\circ}, \gamma_{d}=23 \mathrm{kN} / \mathrm{m}^{3}\right)$ 
This manuscript is the accepted version of the paper:

Reliability analysis of geosynthetic-reinforced steep slopes, Geosynthetics International, Vol. 23, Issue 4, pp. 301 315, https://doi.org/10.1680/jgein.15.00057

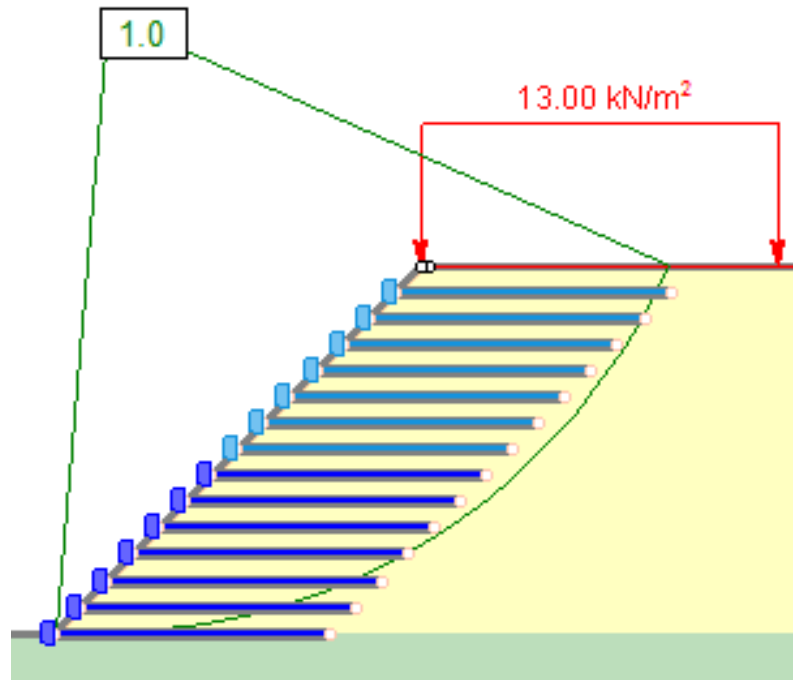

Figure 9. Global Minimum slip surface and over-design factor of Slope $8\left(\alpha=45^{\circ}, L=6.3 \mathrm{~m}\right.$, $\left.\phi_{d}=25^{\circ}, \gamma_{d}=23 \mathrm{kN} / \mathrm{m}^{3}\right)$ 
This manuscript is the accepted version of the paper:

Reliability analysis of geosynthetic-reinforced steep slopes, Geosynthetics International, Vol. 23, Issue 4, pp. 301 315, https://doi.org/10.1680/jgein.15.00057

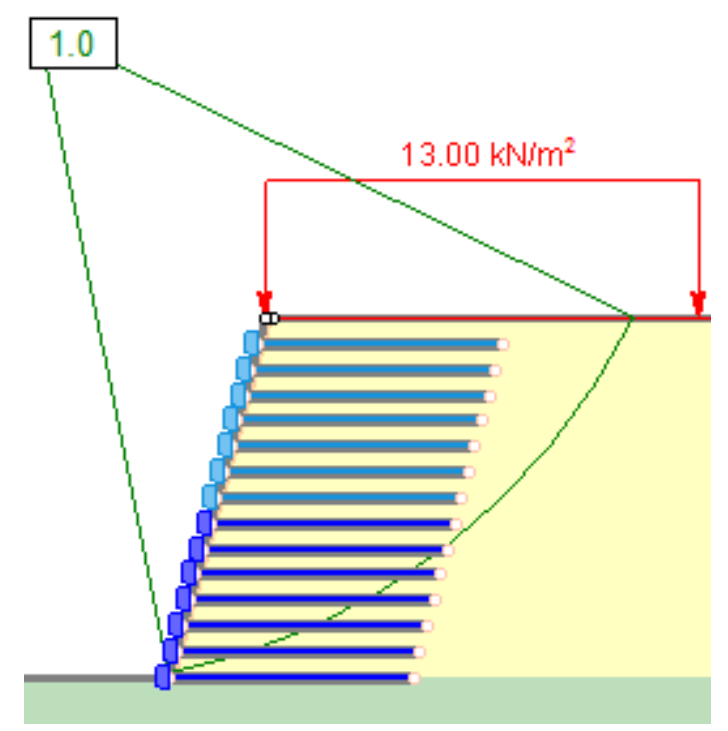

Figure 10. Global Minimum slip surface and over-design factor of Slope $9\left(\alpha=75^{\circ}\right.$, $\left.L=5.8 \mathrm{~m}, \phi_{d}=25^{\circ}, \gamma_{\mathrm{d}}=23 \mathrm{kN} / \mathrm{m}^{3}\right)$ 
This manuscript is the accepted version of the paper:

Reliability analysis of geosynthetic-reinforced steep slopes, Geosynthetics International, Vol. 23, Issue 4, pp. 301 315, https://doi.org/10.1680/jgein.15.00057

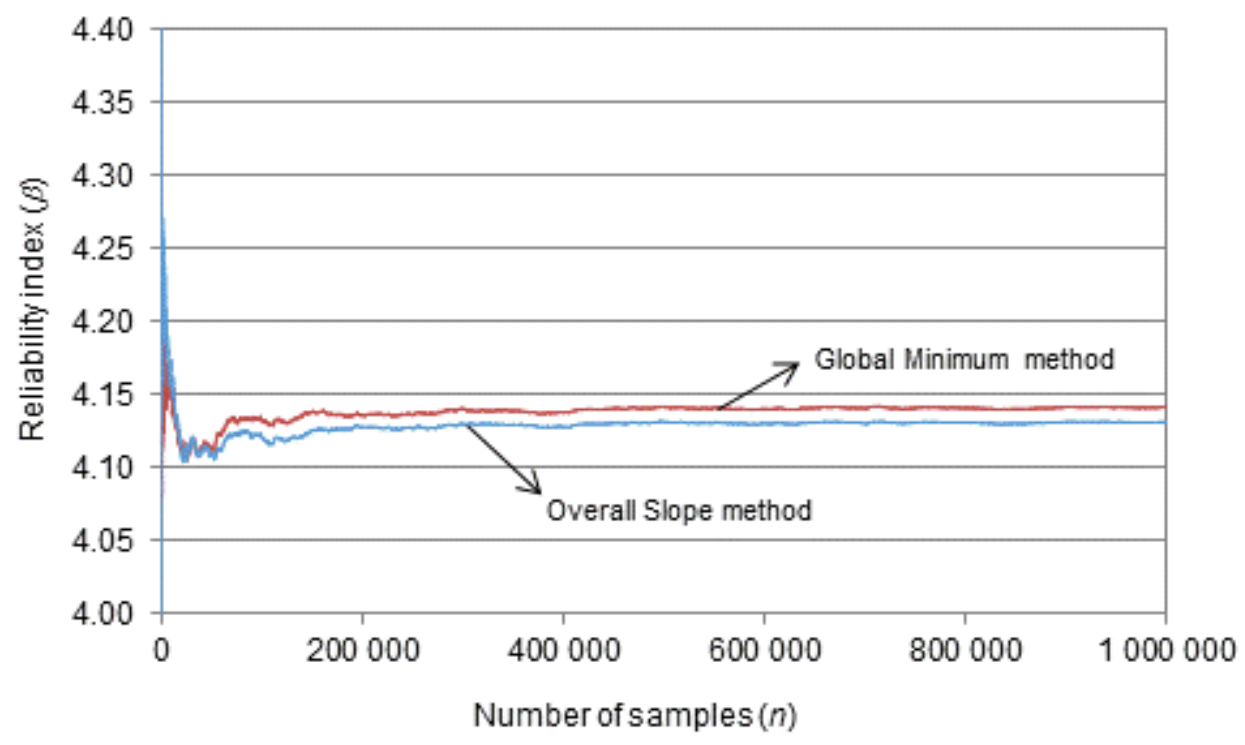

Figure 11. Convergence of the reliability index of Slope 5 (Global Minimum and Overall Slope methods) 
This manuscript is the accepted version of the paper:

Reliability analysis of geosynthetic-reinforced steep slopes, Geosynthetics International, Vol. 23, Issue 4, pp. 301 315, https://doi.org/10.1680/jgein.15.00057

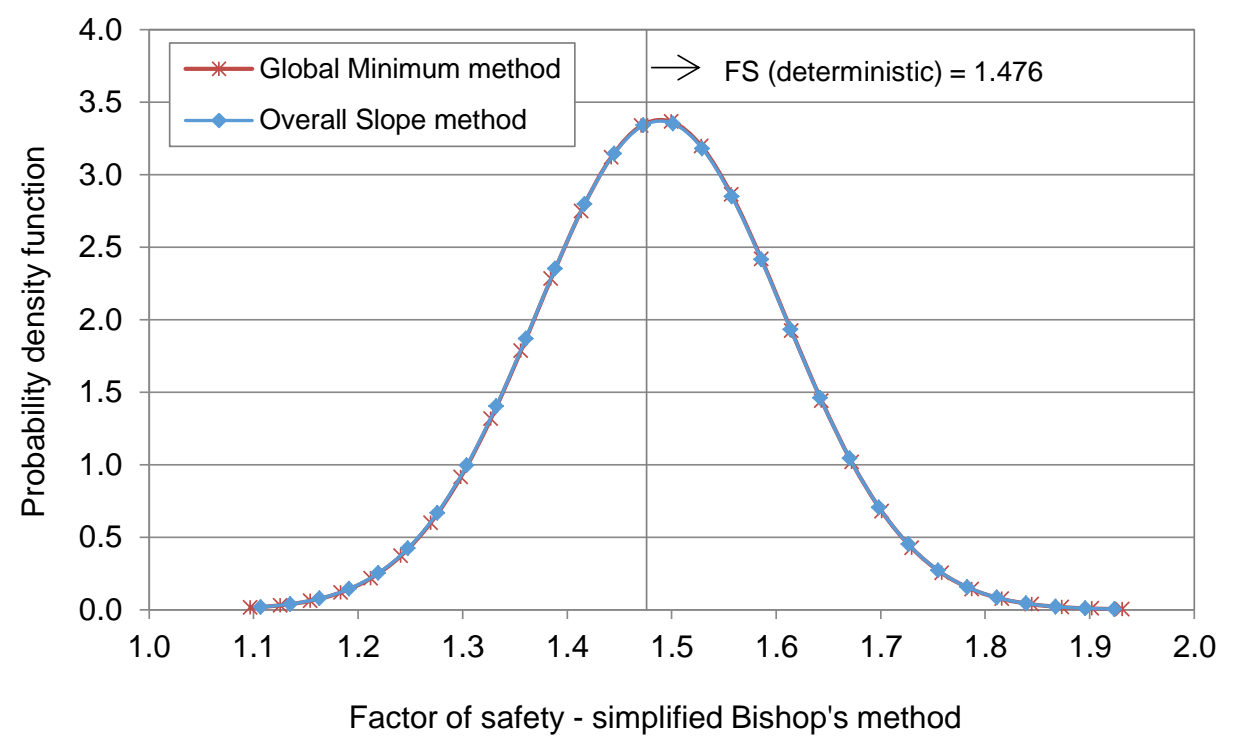

a)

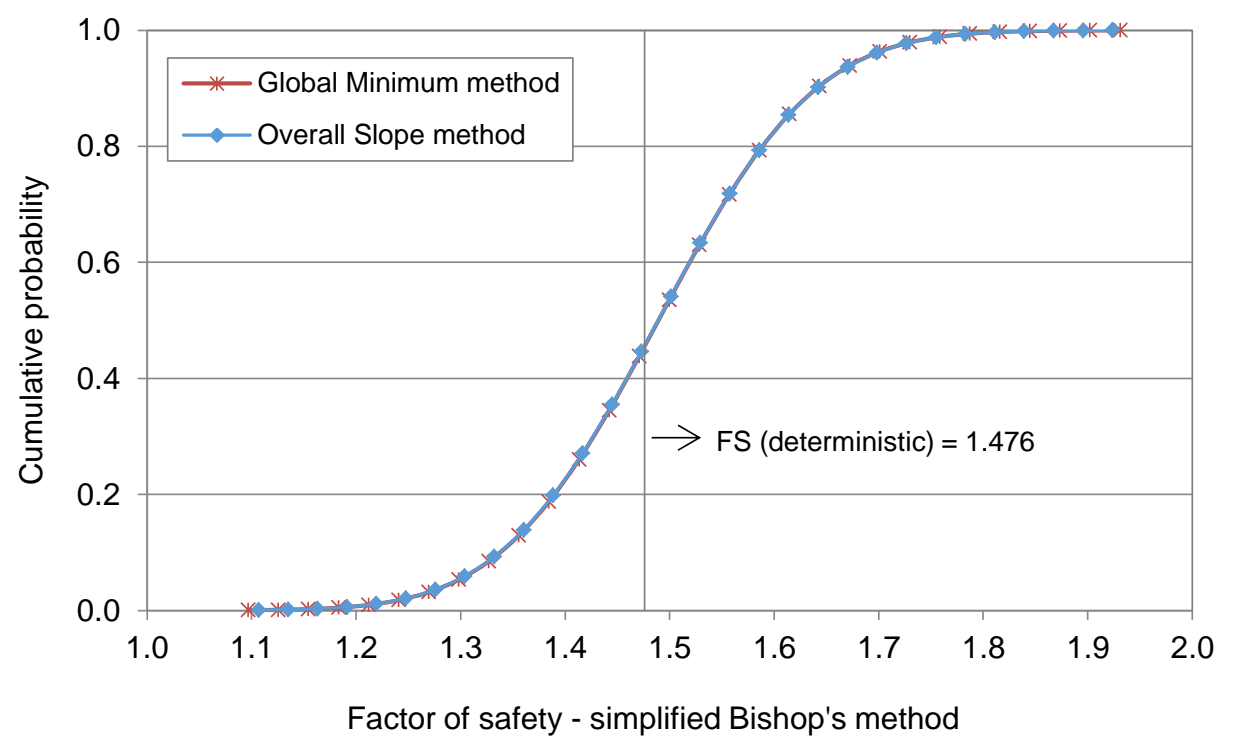

b)

Figure 12. Comparison of results of the probabilistic stability analysis of Slope 5 obtained from the Global Minimum and Overall Slope methods: a) probability density function of the factor of safety; b) cumulative probability distribution of the factor of safety 
This manuscript is the accepted version of the paper:

Reliability analysis of geosynthetic-reinforced steep slopes, Geosynthetics International, Vol. 23, Issue 4, pp. 301 315, https://doi.org/10.1680/jgein.15.00057

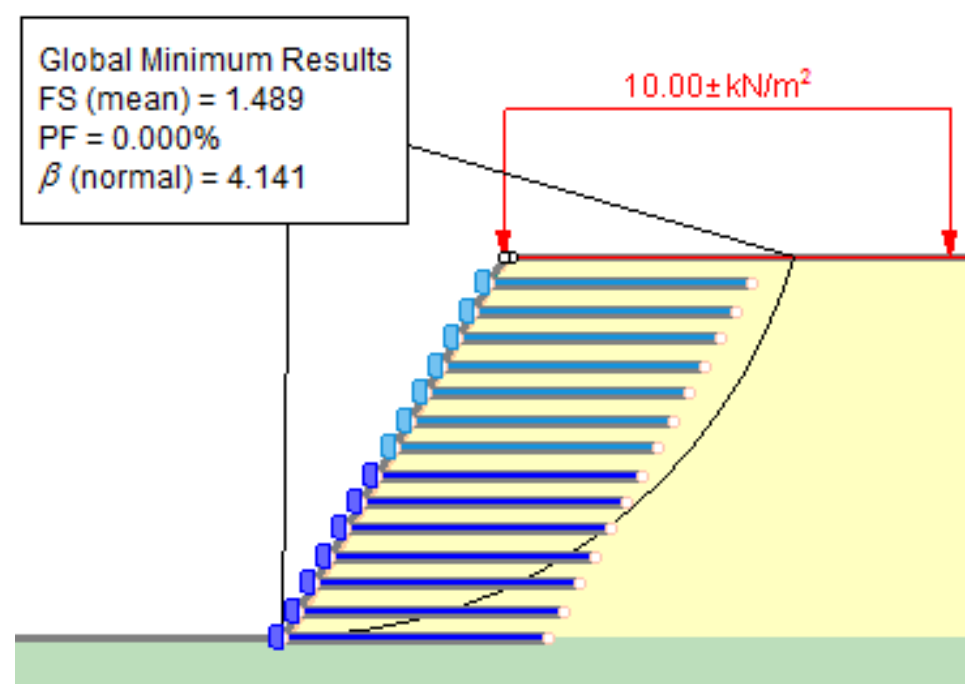

a)

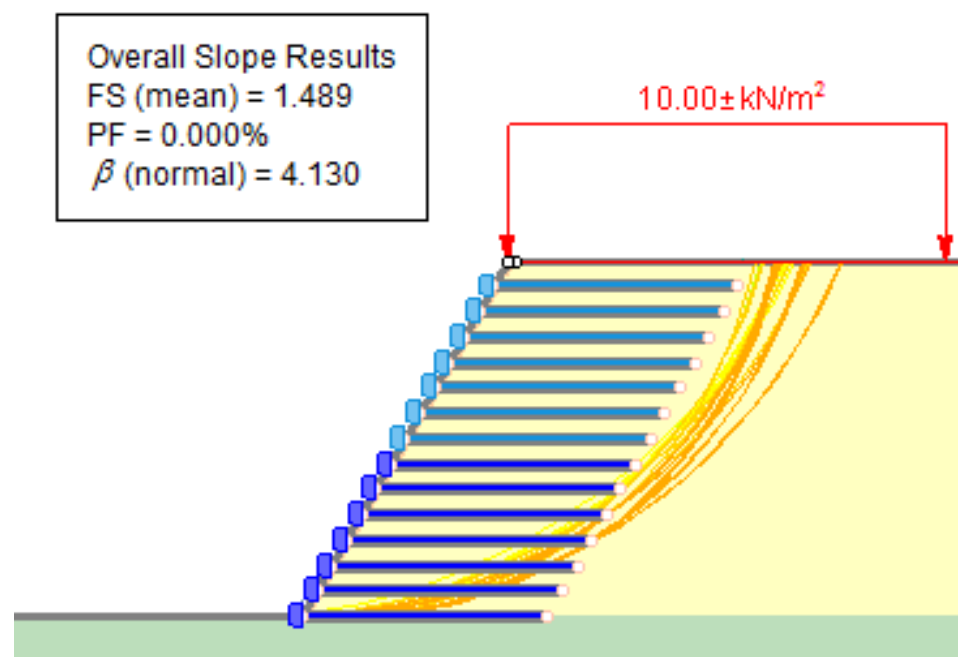

b)

Figure 13. Results of the probabilistic stability analysis of Slope 5: a) Global Minimum method;

b) Overall Slope method 